Article

\title{
Synthesis of Highly Selective and Stable Co-Cr/SAPO-34 Catalyst for the Catalytic Dehydration of Ethanol to Ethylene
}

\author{
Peirong Niu, Xiao Ren, Deyuan Xiong * ${ }^{\mathbb{D}}$, Shilei Ding, Yuanlin Li, Zhaozhou Wei and Xusong Chen \\ Guangxi Key Laboratory of Petrochemical Resource Processing and Process Intensification Technology, School of \\ Chemistry and Chemical Engineering, Guangxi University, Nanning 530004, China; peirongn@st.gxu.edu.cn (P.N.); \\ xiaor@alu.gxu.edu.cn (X.R.); shileid@alu.gxu.edu.cn (S.D.); liyl@st.gxu.edu.cn (Y.L.); \\ zhaozhouw@st.gxu.edu.cn (Z.W.); xusongchen@st.gxu.edu.cn (X.C.) \\ * Correspondence: dyxiong@gxu.edu.cn; Tel.: +86-138-7718-2465
}

Received: 5 June 2020; Accepted: 10 July 2020; Published: 14 July 2020

\begin{abstract}
In this study, silicoaluminophosphate (SAPO)-34 and Me (Me = $\mathrm{Cr}, \mathrm{Co}$ )-modified SAPO-34 were synthesized and used as catalysts to investigate the catalytic performance by means of a probe reaction from ethanol to ethylene. The metal oxides were loaded on the SAPO-34 support via an impregnation method. The synthesized catalysts were characterized using XRD, SEM, EDX, FT-IR, $\mathrm{NH}_{3}$-TPD, BET, and TGA techniques. Compared to SAPO-34, SAPO-34 doped with metal oxides showed the same chabazite (CHA) topology. The structure and properties of the catalyst were further optimized by varying the amount of Me. The experimental results showed that $\mathrm{Co}-\mathrm{Cr} / \mathrm{SAPO}-34$ exhibited the best catalytic performance when the reaction temperature reached $400{ }^{\circ} \mathrm{C}$ at a weight hourly space velocity (WHSV) of $3.5 \mathrm{~h}^{-1}$, for which the single-pass conversion of ethanol was determined as $99.15 \%$, and the selectivity of ethylene was $99.4 \%$ at an optimum catalytic performance in the reaction of up to $600 \mathrm{~min}$. In addition, $\mathrm{Co}-\mathrm{Cr} / \mathrm{SAPO}-34$ exhibited better catalytic activity and anti-coking ability than pure SAPO-34, which was attributed to its enhanced pore structure and moderate acidity. It can also be concluded from the results of this experiment that the performance of the Co-Cr bimetal-supported catalyst is better than that of the $\mathrm{Cr}$ mono-metal catalyst.
\end{abstract}

Keywords: SAPO-34; modification; dehydration; ethanol to ethylene; impregnation

\section{Introduction}

Ethylene, as the core elemental component of the petrochemical industry, is attributed to more products than petrochemical products produced globally. In general, this compound has mainly been produced via fluid catalytic, distillation, and stream cracking processes of crude oil [1,2]. However, the supply of ethylene in recent years has gradually been limited due to the prices of crude oil, which is attributed to the depletion of natural resources. In addition, the fossil fuels are particularly non-renewable, and their continuous production is associated with serious environmental consequences, such as oil spills and damage to aquatic species. At present, moving to renewable energy is seen as one of the viable options to address these issues. Compared to the traditional method of producing ethylene, the conversion route of ethanol to ethylene has attracted more and more attention attributed to its advantages, such as the simplicity in the production process, cost-effectiveness, and an abundant source of raw materials [3-5]. Moreover, the core of ethanol dehydration involves preparation with catalysts of high catalytic activity, which favors stability and high ethylene selectivity.

Recently, the most commonly used supports in the petrochemical sector are $\gamma-\mathrm{Al}_{2} \mathrm{O}_{3}$ and molecular sieves for the conversion of methanol to olefin (MTO) and ethanol to olefin (ETO). In a typical ethanol 
dehydration process using modified $\gamma-\mathrm{Al}_{2} \mathrm{O}_{3}$, the reaction system was demonstrated to be stable with a high yield of ethylene, while a high-level temperature, lower velocity, and higher energy consumption were required for raw ethanol containing a large amount of water [6]. In addition, a zeolite catalyst HZSM-5 has widely been used for MTO reactions, owing to its well-defined pore structure, high specific surface area, and favorable surface acidity [7]. However, HZSM-5 easily leads to coke deactivation due to strong acidity, which tends to reduce its stability and reliability [8]. Silicoaluminophosphate (SAPOs) molecular sieves, a kind of microporous material with a P-Al or Si-P-Al skeleton, SAPO-34, are particularly important catalysts, and they have the chabazite (framework code $\mathrm{CHA}$ ) structure with eight member rings [9], which has widely been applied in the petrochemical industry as a suitable alternative due to its unique acid-base characteristics, large specific surface area, and high selectivity to light olefins in MTO processes [10-12]. Moreover, the production of coke in the reaction process is considered to be the major phase for the deactivation of the SAPO-34 catalyst. This mainly occurs due to the presence of large cavities, which allows the passage of alkylated benzene molecules and their protonic counterparts, thereby converting these species into larger aromatics that completely block access to any active site in the SAPO-34 channel, thus affecting catalytic performance [13]. The metal (Me)-modified SAPO-34 support (MeSAPO-34) system is one of the main methods to effectively optimize catalytic performance [14-16]. The modification of SAPO-34 with metals has been reported to modify the zeolite textural properties and affect the selectivity to the hydrocarbon species. Sedighi et al. [2] studied the effect of metal-incorporated SAPO-34 on its catalytic performances in the MTO process $\left(\mathrm{Me}=\mathrm{Fe}, \mathrm{Co}, \mathrm{Ni}, \mathrm{La}\right.$ and $\mathrm{Ce}$ ) at $425^{\circ} \mathrm{C}$ and $1 \mathrm{bar}$, and the deduced results showed that the incorporation of metal ions improved ethylene production and effectively enhanced the catalysts' lifespan. Kang and co-workers [17], in another study on prepared MeAPSO-34s ( $\mathrm{Me}=\mathrm{Fe}, \mathrm{Co}, \mathrm{Ni}$ ) catalyst by the rapid crystallization method, depicted the enhancement of methanol conversion in the reaction at $450^{\circ} \mathrm{C}$ for $1 \mathrm{~h}$, compared to the CoAPSO- 34 catalyst that exhibited a minor methanation. It was well known that the formation of methane was usually accompanied by rapid deactivation due to extra hydrogen being drawn out from the residual hydrocarbons; thus, the lifetime of CoAPSO-34 may be correspondingly prolonged. Another investigation by Hotevar and Levec [18] that involved the preparation of MeAPSO-34 $(\mathrm{Me}=\mathrm{Co}, \mathrm{Mn}, \mathrm{Cr}$ ) catalyst via an isomorphous substitution method showed that CrAPSO-34 possessed better catalytic activity than CoAPSO-34 and MnAPSO-34 catalysts, and the selectivity for the formation of low olefins was observed to decrease rapidly with time on stream for MeAPSO-34 as a consequence of coking. Alternatively, the hydrocarbon pool (HCP) mechanism followed by MTO reaction, which involves the addition of methanol, was subsequently put onto an organic scaffold $[13,19]$. It was also found that an almost identical product distribution was obtained between MTO and ETO reactions [20]. This indicated that the trapped species within the zeolite channels after ETO reaction were similar to those derived after MTO. This suggested that the ETO process may also follow HCP pathways [21]. Furthermore, it has also been reported that the modification of zeolite with transition metals affects the selectivity of hydrocarbon compounds by changing the structural properties of zeolite [22]. At present, there are many reports on the application of the modified SAPO-34 molecular sieve to MTO, but relatively few reports on the application of the modified SAPO-34 molecular sieve to the reaction of ethanol to ethylene. In the reaction of methanol to olefin, the modified SAPO-34 of $\mathrm{Co}$ and $\mathrm{Cr}$ showed good catalytic performance. However, to the authors' best knowledge, there has been no systematic study that reports on Co- and $\mathrm{Cr}$-modified SAPO-34 for ethanol dehydration into ethylene by the impregnation method. The research [8] revealed that NiAPSO-34 showed excellent performance for ethylene production from ethanol: The conversion of ethanol was $96.5 \%$ for NiAPSO- 34 at $375{ }^{\circ} \mathrm{C}$ and the maximal ethylene selectivity was $98.3 \%$ at $350^{\circ} \mathrm{C}$ and an LHSV (liquid hourly space velocity) of $3 \mathrm{~h}^{-1}$. In addition, it has been reported that the incorporation of $\mathrm{Mn}$ and $\mathrm{Zn}$ into the SAPO-34 structure can effectively improve the ethanol conversion and ethylene selectivity, and the best yield of ethylene was up to $97.8 \%$ over Mn-SAPO-34 at optimal reaction conditions: Loading amount $5 \%$, WHSV $2 \mathrm{~h}^{-1}$, reaction temperature $340{ }^{\circ} \mathrm{C}$ [6]. Unfortunately, the catalytic performance was maintained constant with a slow reduction with the 
extension of time in $600 \mathrm{~min}$. Herein, metal-modified Me/SAPO-34 $(\mathrm{Me}=\mathrm{Co}, \mathrm{Cr})$ catalysts were synthesized via the impregnation method in this work. In addition, a detailed catalyst representation was used to reveal whether the introduction of metals was the correct method of improving catalytic performance and extending the lifespan of the catalyst. The synthesized materials were then studied by XRD, SEM, EDX, FT-IR, $\mathrm{NH}_{3}$-TPD, and BET, and analyzed for thermal stability of the applied catalysts via TGA. Finally, we also investigated the optimal conditions of the modified catalysts following a dehydration reaction process from ethanol to ethylene. This work will build a foundation to industrial production of ethylene by the bio-ethanol dehydration process with economic value and strategic significance.

\section{Results}

\subsection{XRD Anaysis}

The X-ray diffraction (XRD) analysis of $\mathrm{Cr} / \mathrm{SAPO}-34$ and $\mathrm{Co}-\mathrm{Cr} / \mathrm{SAPO}-34$ is represented in Figure 1. The results indicated that SAPO-34 zeolite doped with different metals was successfully synthesized. The appearance of characteristic diffraction peak positions and shapes were similar. The main peaks of the SAPO-34 support $(2 \theta=10.1,14.9,21.3,26.7$ and 31.7$)$ were observed in all the analyzed samples, which indicated that the addition of metal elements had no significant effect on the structure of the molecular sieves, and the CHA structure of SAPO-34 was retained [23,24]. Moreover, no additional peaks were observed in the XRD patterns of any of the samples. It is apparent from the XRD analysis that $\mathrm{Cr} / \mathrm{SAPO}-34$ and $\mathrm{Co}-\mathrm{Cr} / \mathrm{SAPO}-34$ were successfully synthesized. The observed diffraction peaks at $37^{\circ}$ and $57^{\circ}$ were attributed to the $\mathrm{CoO}$, which confirmed the incorporation of the metal element on modified catalysts [25]. However, no obvious diffraction peaks of $\mathrm{Cr}_{2} \mathrm{O}_{3}$ were observed [26], suggesting that $\mathrm{Cr}_{2} \mathrm{O}_{3}$ might have been highly dispersed on the surface of the SAPO-34 support [27]. In general, the dispersion increased as the grain size decreased and vice versa. In a catalytic reaction, the reactants need to be in full contact with the surface atoms, so it is speculated that the catalytic performance improved with the increase in metal oxides dispersion.

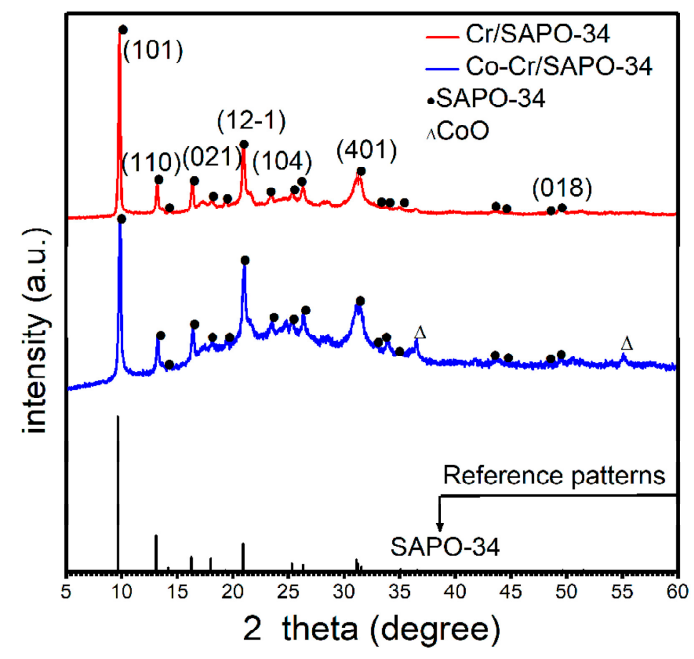

Figure 1. Representation of the XRD patterns for the different catalysts.

\subsection{SEM Analysis}

Scanning electron microscope (SEM) images of SAPO-34 catalysts before and after modification are shown in Figure 2. It is observed that the synthesized SAPO-34 molecular sieve with smooth and relatively complete cubic structures was approximately $3 \mu \mathrm{m}$ in size. On the other hand, the cubic structure of $\mathrm{Cr} / \mathrm{SAPO}-34$ and $\mathrm{Co}-\mathrm{Cr} / \mathrm{SAPO}-34$ particles prepared via the impregnation method ranged from 1 to $3 \mu \mathrm{m}$, showing some defects with several non-homogenous edges of the unit cell and debris 
around the catalysts. The impregnation process includes both adsorption and penetration into the pores. After the metal impregnation and during the calcination at $600{ }^{\circ} \mathrm{C}$, chromic nitrate nonahydrate and cobalt nitrate hexahydrate species on the surface of SAPO-34 were decomposed, and in this situation, an interaction between metal species and Brønsted acid sites can be created. The metal oxide distribution of small particles can be seen on the surface of the catalyst and, thus, reduce the smoothness of the crystal surface. Cr/SAPO-34 catalyst particles were uniformly distributed with the presence of coated amorphous particles on the surface of the molecular sieve. However, the amorphous particles presented on the surface of the $\mathrm{Co}-\mathrm{Cr} / \mathrm{SAPO}-34$ molecular sieve was depicted to be numerous and messy, as well as partially scattered around the cubic catalyst particles. This may be attributed to the re-aggregation effect of the SAPO-34 during the impregnation method. In essence, this presents one piece of evidence that metal oxides were successfully loaded onto the pore surface of SAPO-34 [6,28]. Moreover, the coffin-shaped structure of the modified catalyst was relatively complete, which indicated that the CHA structure did not change during impregnation, consistent with the previous SEM analysis results. In comparison to the single metal oxide, the addition of the bimetallic elements were more likely to affect the shaped structure of the molecular sieve, attributed to the ease of occurrence of agglomeration at the calcination process prompted by the higher content of the bimetallic oxides.
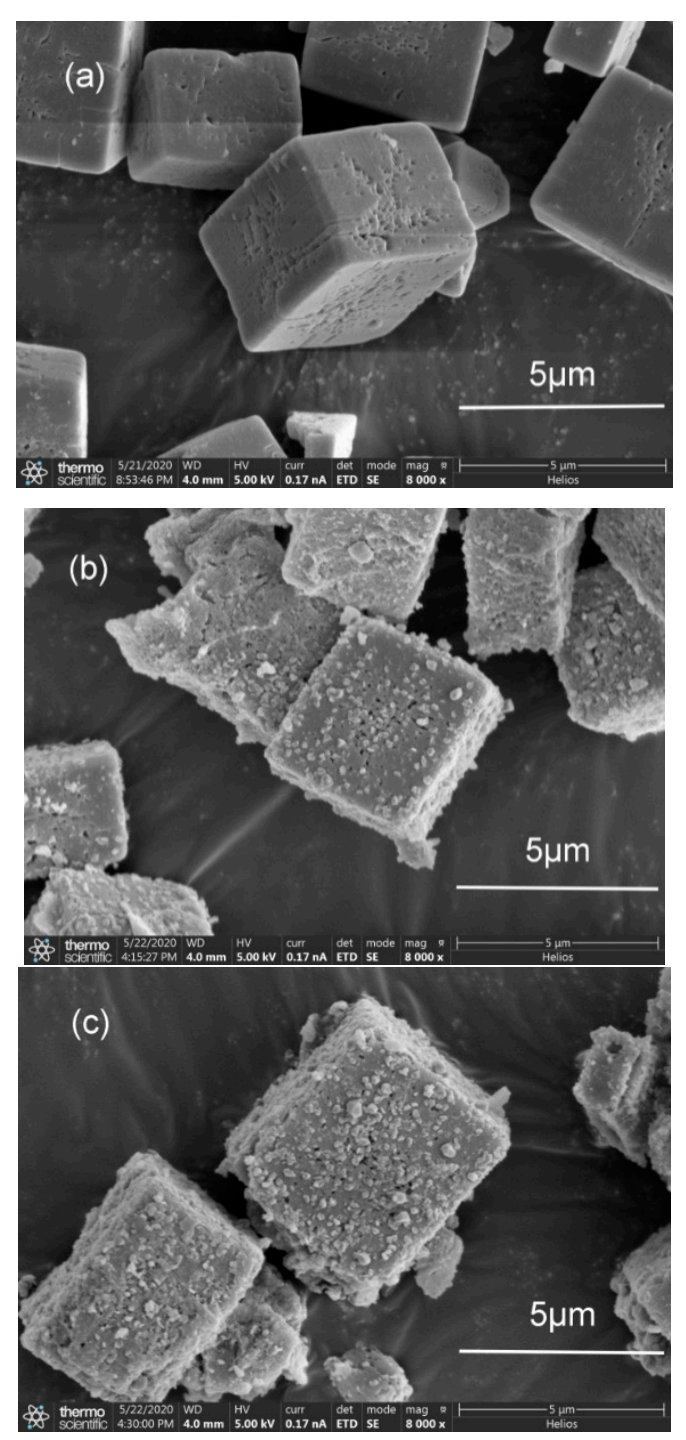

Figure 2. SEM images of (a) silicoaluminophosphate (SAPO)-34, (b) Cr/SAPO-34, and (c) Co-Cr/SAPO-34 catalysts. 


\subsection{EDX Analysis}

Based on the qualitative analysis of the energy of the characteristic $X$ rays, the element concentration analysis was colored differently depending on the different elements, which can use the different colors to represent the pseudocolor map, and it shows the digital relationship between the concentrations of the elements in the sample. Positions and concentrations of different elements can be located with multi-elemental X-ray dot-mapping analysis, acquired information about all elements in a specimen. The EDX element analysis results of the obtained nanostructured catalysts are shown in the Figure 3, and oxygen, phosphorus, aluminum, silicon, chromium, and cobalt elements were detected. As seen, the distribution of the elements was very homogenous on the surface of samples. The Cr element was observed in the modified catalyst, although no obvious peak could be observed in the XRD, proving that the $\mathrm{Cr}_{2} \mathrm{O}_{3}$ was successfully loaded on the SAPO-34 in the form of an amorphous phase. By using the impregnation method, the $\mathrm{Cr}$ and $\mathrm{Co}$ species were placed on the external surface of crystals and inner space of the channels. In addition, the presence of $\mathrm{Cr}$ and Co heteroatoms and oxygen in the corresponding point mapping indicated the successful synthesis of SAPO-34 and the formation of metal oxides. These results also demonstrate no impurities during the synthesis process. In addition, the crystal composition of the synthetic catalyst is shown in the table of Figure 3, and this analysis was applied locally, which indicated a high credibility of the mass percentages in the synthesized catalyst.

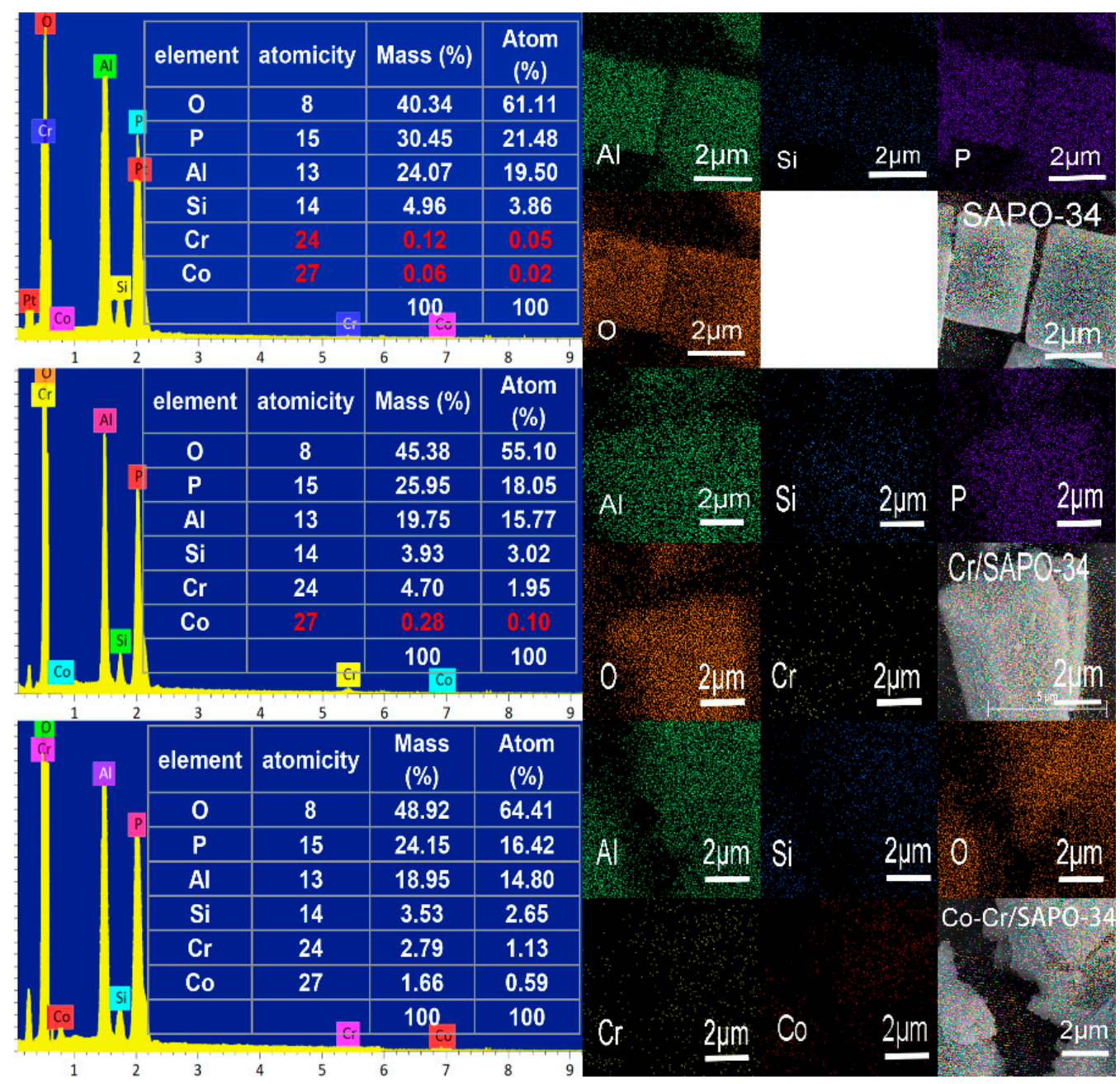

Figure 3. EDX dot-mapping analysis of nanostructured SAPO-34, Cr/SAPO-34, and Co-Cr/SAPO-34 catalysts. 


\subsection{FT-IR Analysis}

FT-IR spectra of the synthesized catalysts are shown in Figure 4. As seen, the characteristic peaks of SAPO-34 are consistent with those reported in the literature [9]. The peak at $490 \mathrm{~cm}^{-1}$ was assigned to the bending of the silicon tetrahedron, and the peak at $635 \mathrm{~cm}^{-1}$ was due to the bending of the D- 6 rings, which confirmed the formation of the CHA structure for all of the catalysts, consistent with the XRD and SEM analysis. The peaks at wavenumbers of about 710, 870, and $1110 \mathrm{~cm}^{-1}$ were assigned to the asymmetric stretching of O-P-O, protonated template, and T-O-T symmetric stretching, respectively. In general, when heteroatoms substituted the framework of molecular sieves, new characteristic peaks were generated, and the intensity of these characteristic peaks increased with the number of heteroatoms into the skeleton. In addition, if the amount of heteroatoms was relatively small, these characteristic peaks would obviously not appear, which would cause the original absorption peak to shift, namely redshift, neither of which are observed in Figure 5. It can be concluded that metals did not exist by the crystal substitution method. Combined with XRD and EDX, this demonstrated that the metal oxides were successfully loaded on the SAPO-34 by impregnation. The peaks at wavenumbers of about 1650 and $2350 \mathrm{~cm}^{-1}$ can be related to physically adsorbed water and $\mathrm{CO}_{2}$ from the atmosphere. The peak at approximately $3450 \mathrm{~cm}^{-1}$ was assigned to the bridging hydroxyl group, including the $\mathrm{Si}-\mathrm{OH}-\mathrm{Al}$ (Brønsted acid position) and the internal P-OH and Si-OH (Lewis acid position). Acid sites have an important influence on the lifetime and activity of catalysts. As seen, by metal impregnation for the synthesized sample, the modified catalysts exhibited much more intense peaks of bridging hydroxyl groups, indicating that metal loading has a positive effect on the formation of $\mathrm{OH}$ groups. FT-IR analysis provided information only about the amount of acid sites, not their strength or type, and judgment about the strength of acid sites by FT-IR is limited. In the next section, we will discuss the concentration and strength of acid sites in detail.

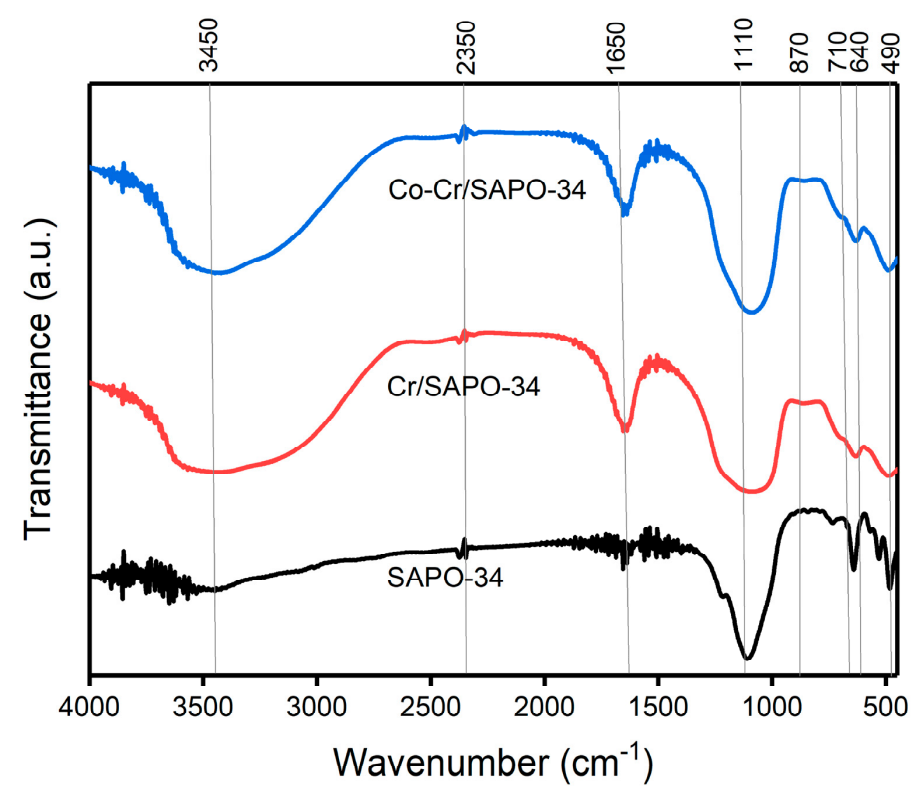

Figure 4. FT-IR spectra of different catalysts: SAPO-34, Cr/SAPO-34, and Co-Cr/SAPO-34 catalysts. 

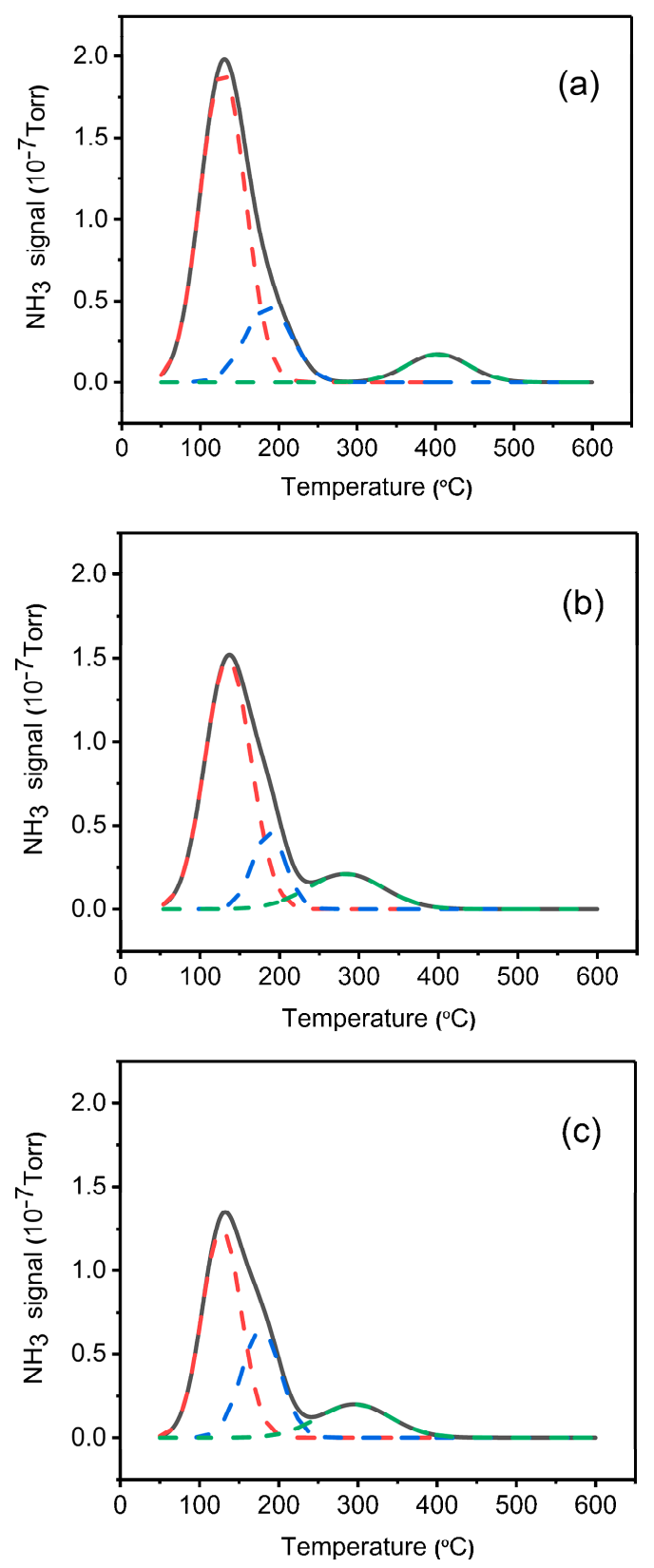

Figure 5. $\mathrm{NH}_{3}$-TPD patterns of the different prepared catalysts: (a) SAPO-34, (b) Cr/SAPO-34, and (c) Co-Cr/SAPO-34.

\section{5. $\mathrm{NH}_{3}-\mathrm{TPD}$ Analysis}

Desirable acidity sites and strength are important factors that affect the performance of SAPO-34 catalysts, as well as the intensity distribution of acidity active sites related to the peak intensity. The area under the TPD curve is proportional to the total number of acid centers of the catalyst, and the acid strength distribution of the active centers is related to the peak strength. Figure 5 illustrates the different intensities of acidity sites among the prepared catalytic samples. Obviously, catalysts $\mathrm{Cr} / \mathrm{SAPO}-34$ and $\mathrm{Co}-\mathrm{Cr} / \mathrm{SAPO}-34$ show the $\mathrm{NH}_{3}$-TPD curves with two peaks as SAPO-34 does. The acidities of weak and strong acids were estimated from the peak area derived using Gaussian fitting of the $\mathrm{NH}_{3}-\mathrm{TPD}$ profiles in the temperature ranges of $100-275{ }^{\circ} \mathrm{C}$ and $275-600^{\circ} \mathrm{C}$, respectively [28]. Logically, the strong Brønsted sites may have been generated by $\mathrm{Si}$ and/or metal ions in the SAPO-34 framework, while the weak acid sites were associated with the defective structural $\mathrm{OH}$ groups (including weak acid $\mathrm{Si}-\mathrm{OH}$, $\mathrm{P}-\mathrm{OH}$, and $\mathrm{Al}-\mathrm{OH})[29,30]$. The reaction of ethanol dehydration to diethyl ether was mainly performed 
on the weak acidity center, and the further conversion of diethyl ether to lower olefins was carried out on the strong acid center. Compared to the SAPO-34 support, the peak of the strong acidity of catalysts was observed to shift toward lower temperature, indicating that the loading of metal oxides changed the concentration and strength of the acidity sites during the impregnation and calcination process [31]. The area of the weak acid peak and strong acid peak of the modified catalysts was smaller than that of SAPO-34, and this proved that the acid site of ammonia adsorption and the amount of acid sites decreased.

Table 1 shows the acidity and strength distribution of different catalysts. As presented, compared to the SAPO-34 support, the total acidity of $\mathrm{Cr} / \mathrm{SAPO}-34$ and $\mathrm{Co}-\mathrm{Cr} / \mathrm{SAPO}-34$ decreased, especially the content of weak acid, while the content of strong acid increased. The phenomena may be ascribed to the additional bonding to the acidity sites created by the incorporation of the metal components. In general, the substitution of phosphorus with silica results in the production of Brønsted acid sites, where the replacement of phosphorus with other metals (chromium and cobalt) will not produce Brønsted acid centers, resulting in a reduction in the density of Brønsted acid sites. In essence, the metal oxides block the acid sites, leading to the decrease in total acidity while, at the same time, providing alternative new acidity sites, due to partial exchange of $\mathrm{Cr}^{3+}$ and $\mathrm{Co}^{2+}$ ions for $\mathrm{H}^{+}$ions in zeolites during the metallic oxides loading procedure [31]. When the ionic valency is high, the polarization is stronger and more proton acid can be produced, which is why $\mathrm{Co}-\mathrm{Cr} / \mathrm{SAPO}-34$ is slightly more acidic than $\mathrm{Cr} / \mathrm{SAPO}-34$. Conversion of ethanol to diethyl ether may occur in the weak acid sites, while the further conversion of light olefins by diethyl ether was carried out on the strong acid center. Therefore, the distribution of the acid sites was reasonably distributed in the center and the acidity was moderate, and it is expected that the modified SAPO-34 catalyst with the proper distribution of acid sites and moderate strength of acidity will show good catalytic performance in ethanol dehydration reaction. Presumably, a strong acid with the subsequent measurement of catalytic performance may promote the production of ethylene, but by increasing the strength of the acid, the tendency for hydrogen transfer reactions and coke formation would be increased. After metal modification, the zeolite molecular sieve can produce Brønsted acid sites by cationic exchange $\left(\mathrm{Cr}^{3+}, \mathrm{Co}^{2+}\right)$ with positive ions, and then produce Lewis acid sites by dehydration, producing carbocation with the reactant ethanol. According to the transformation mechanism of ethanol to produce ethylene, ethanol molecules are first chemically adsorbed on the active sites of the catalysts to produce vinyl carbocation, and then converted into ethylene [6]. The next experimental results in this study showed that ethanol dehydration was an acidity-dependent reaction and the zeolites with low acidity were more selective to the formation of ethylene. In conclusion, the loading of different metal oxides on the SAPO-34 has an effect on the acidity of the catalyst.

Table 1. Acidity and strength distribution of catalysts.

\begin{tabular}{cccc}
\hline \multirow{2}{*}{ Samples } & \multirow{2}{*}{ Total Acidity/(mmol/g) } & \multicolumn{2}{c}{ Percentage of Acid Sites $\mathbf{( \% ~ o f ~ T o t a l ~ A c i d ) ~}$} \\
\cline { 3 - 4 } & & Weak Acid & Strong Acid \\
\hline SAPO-34 & 0.77 & 73 & 27 \\
Cr/SAPO-34 & 0.65 & 69 & 31 \\
Co-Cr/SAPO-34 & 0.67 & 55 & 45 \\
\hline
\end{tabular}

\subsection{BET Analysis}

Figure 6a showed the $\mathrm{N}_{2}$ adsorption-desorption isotherms for the different catalysts. According to the IUPAC (2015) classification, SAPO-34 showed the typical type-III isotherm, which indicated the existence of mesoporous materials, namely, the secondary pores [32]. Cr/SAPO-34 and $\mathrm{Co}-\mathrm{Cr} / \mathrm{SAPO}-34$ catalysts exhibited a typical indicative I-type isotherm without any hysteresis loop. In general, I-type isotherms often reflect the phenomenon of micropore filling on the microporous adsorbent (molecular sieves, microporous activated carbon), and the saturation adsorption value is equal to the filling volume of the micropore, confirming the presence of microporous structures, which may be due to the fact that small 
$\mathrm{Cr}_{2} \mathrm{O}_{3}$ and $\mathrm{CoO}$ particles could easily have been deposited in the pores of the supports and subsequently block. The pore size distribution of the three catalysts obtained by the Barrett-Joyner-Halenda (BJH) method is shown in Figure 6b. As observed, the pore distribution of the modified SAPO-34 catalysts was lower than that of SAPO-34, which may be attributed to metal oxides coated on the surface of the catalyst particle (as shown in the SEM images) when the content was low. However, this may have caused partial pore blockage in the catalyst by metal species crystallites derived from the impregnation process or the sintering of metal oxides when the content of metals was excessive.
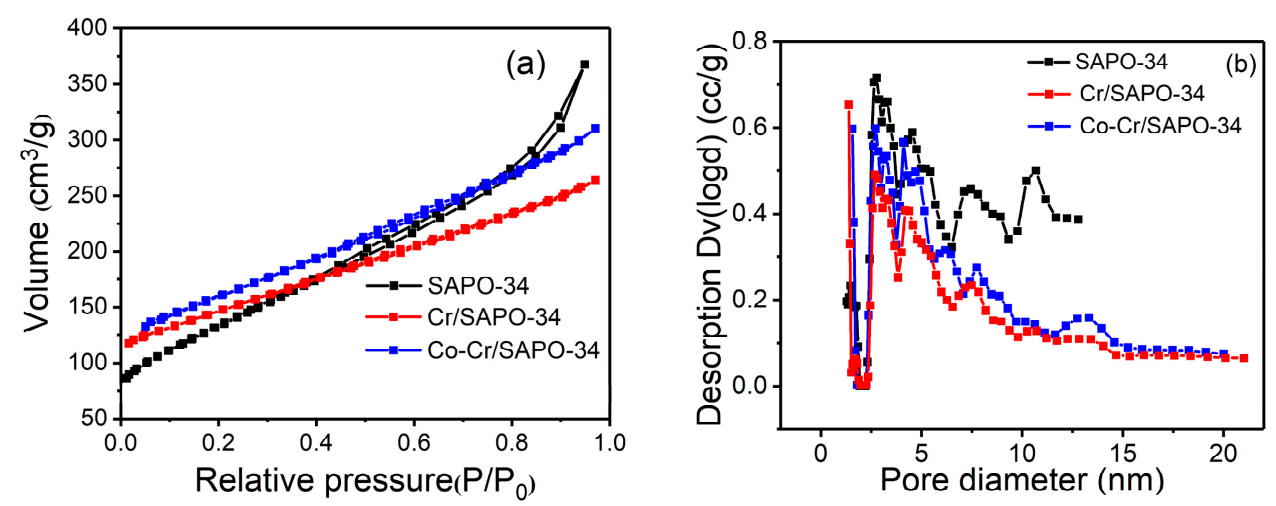

Figure 6. (a) $\mathrm{N}_{2}$ adsorption-desorption isotherms and (b) pore size distribution of SAPO-34, Cr/SAPO-34, and Co-Cr/SAPO-34 catalysts.

The $\mathrm{N}_{2}$-physisorption results for the different catalysts are listed in Table 2. Evidently, all modified catalysts showed a higher specific surface area than SAPO-34. This was due to the fact that the metal oxides could have been deposited on the support catalyst, thereby increasing the specific surface area of the molecular sieves, which possibly promoted the conversion of ethanol by enhancing the contact surface between ethanol and the molecular sieve. Thus, the larger specific surface area in the present study was expected to play an important role in contributing to the catalytic activity. At the same time, the average pore size of the molecular sieve was reduced to convert the mesoporous molecular sieve to microporous, which may impart a diffusion barrier and influence product diffusion in the micropores, resulting in an increase in shape selectivity. It could effectively inhibit the progress of the secondary reaction and reduce the generation of byproducts [22]. According to the shape-selective catalysis theory, the critical diameter of the reactant ethanol molecule is smaller than the pore diameter of the catalyst, so it can enter into the catalyst pore and contact with the inner surface of the catalyst for catalytic reaction, which is helpful for reactant shape selection catalysis. The reaction product ethylene molecule whose critical diameter is smaller than the pore diameter can escape from the pore and become the final product, while the product whose critical diameter is larger than the pore diameter cannot escape from the pore, resulting in product selectivity. As the pore size becomes smaller, the higher hydrocarbon compounds cannot escape, thus improving the selectivity.

Table 2. Textural properties of the catalysts.

\begin{tabular}{cccc}
\hline Catalysts & $\mathrm{S}_{\text {BET }}\left(\mathbf{m}^{2} / \mathbf{g}\right)$ & $\mathbf{V}_{\text {total }}\left(\mathrm{cm}^{3} / \mathbf{g}\right)$ & $D_{\text {pore }}(\mathbf{n m})$ \\
\hline SAPO-34 & 483 & 0.57 & 2.35 \\
Cr/SAPO-34 & 517 & 0.41 & 1.64 \\
Co-Cr/SAPO-34 & 563 & 0.48 & 1.70 \\
\hline
\end{tabular}

\subsection{Coke Formation}

The thermal stabilities of the used catalysts were investigated by thermogravimetric analysis (TGA) to determine the presence of formed coke. The coke amount of the used catalysts and the mass loss relationship 
of the catalyst samples as a function of temperature are shown in Figure 7. Evidently, two weight loss stages are observed in the TGA curves. The first weight occurred below $300{ }^{\circ} \mathrm{C}$ and is ascribed to the sufficient removal of physically adsorbed water, while the weight loss at the temperature from 300 to $800{ }^{\circ} \mathrm{C}$ was attributed to the formation of coke [27]. The weight loss ratio of coke was much lower than the physically adsorbed water. The weight loss from coke calcination of $\mathrm{Cr} / \mathrm{SAPO}-34$ and $\mathrm{Co}-\mathrm{Cr} / \mathrm{SAPO}-34$ catalysts was $1.4 \%$ and $3.2 \%$, respectively, which was less than the SAPO- 34 catalyst of $8.2 \%$ reported in the literature [32]; therefore, it is speculated that the modified catalyst has better anti-coking performance than the SAPO-34 support. As can be seen from the $\mathrm{NH}_{3}$-TPD results, the modified catalysts with metal species reduced the amount of acid sites than SAPO-34, thus considerably decreasing the coke deposition of the catalyst [33]. This is why the modified catalyst has less carbon deposition than the SAPO-34 support. During the dehydration of ethanol into ethylene, the formation of amorphous coke on the surface and within the pores of the catalyst would cover the acid site and block the pore entrances, eventually leading to deactivation of the catalysts; stronger acid sites promote more coking reaction. The result of the $\mathrm{NH}_{3}-\mathrm{TPD}$ provides evidence that the $\mathrm{Co}-\mathrm{Cr} / \mathrm{SAPO}-34$ catalyst brought about more strong acid sites, which explains the higher coke deposition for the $\mathrm{Co}-\mathrm{Cr} / \mathrm{SAPO}-34$ than the $\mathrm{Cr} / \mathrm{SAPO}-34$ catalyst. Coke formation occurred mostly due to reactions such as oligomerization, dehydrogenation, and hydrogen transfer, which are mainly related to the strength and amount of acid sites on the catalyst surface [33]. The mechanism of ethanol conversion is similar to methanol conversion to hydrocarbons, but direct dehydration of ethanol for ethylene eliminates the need for an indirect pathway of carbon-carbon coupling, such as the hydrocarbon pool mechanism. Firstly, ethanol is dehydrated to produce ethylene, which, in a series of side reactions, produces higher hydrocarbons. The hydrocarbon formation process is shown in Figure 8.

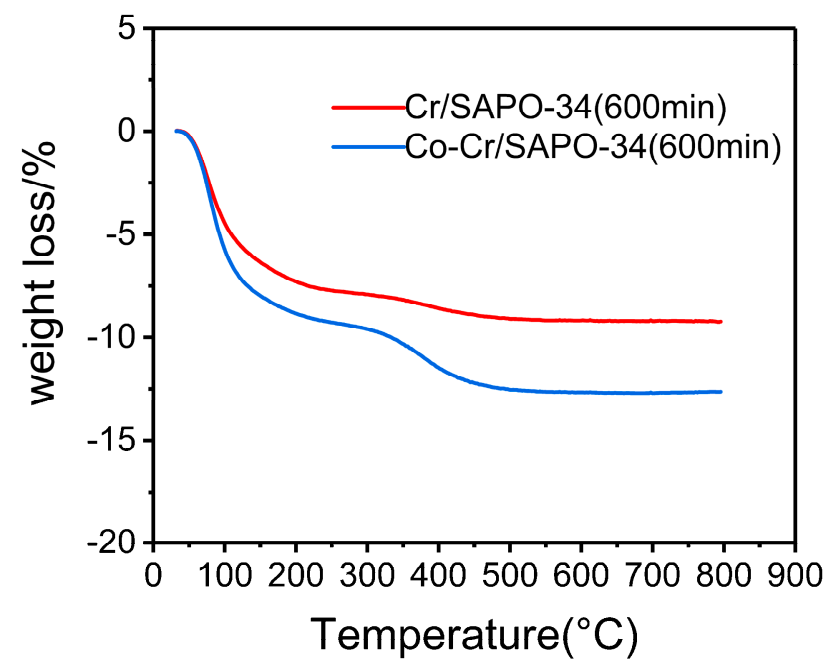

Figure 7. Thermal analysis of discharged Cr/SAPO-34 and Co-Cr/SAPO-34 used after $600 \mathrm{~min}$.

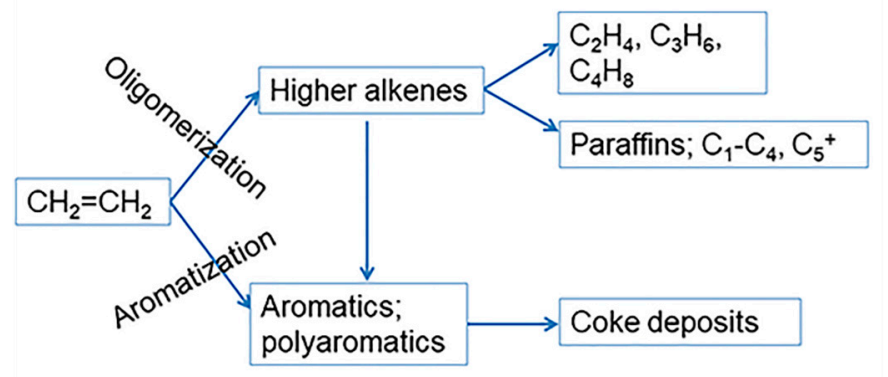

Figure 8. Process of hydrocarbons formation from ethanol. Adapted from: Reference [33]. 


\section{Activity Tests of Catalysts}

In order to study the influence of metal content on catalyst performance, the catalysts with different metal oxides were used in the fixed bed reactor at $400{ }^{\circ} \mathrm{C}$ at a WHSV of $3.5 \mathrm{~h}^{-1}$ and a catalyst amount of $0.5 \mathrm{~g}$. The obtained results are shown in Figure 9. As observed, the catalytic activity of Cr-based catalysts first increased and was then followed by a gradual decrease. The Cr/SAPO-34 catalyst exhibited excellent catalytic performance when the $\mathrm{Cr}$ content was $2 \mathrm{wt} \%$, for which the ethanol conversion and ethylene selectivity were determined as $97.3 \%$ and $97.9 \%$, respectively. Further investigating the influence of bimetallic oxides on catalytic activity, the content of Co was varied on the basis of keeping the content of $\mathrm{Cr}$ constant at $2 \mathrm{wt} \%$. Once the Co content reached $1.5 \mathrm{wt} \%$, the $\mathrm{Co}-\mathrm{Cr} / \mathrm{SAPO}-34$ catalysts showed better catalytic activity ( $99.3 \%$ ethanol conversion and $99.4 \%$ ethylene selectivity), which was better than the $\mathrm{Cr} / \mathrm{SAPO}-34$ catalyst. This suggested that the introduction of $\mathrm{Cr}$ and $\mathrm{Co}$ was both beneficial to enhance the performance of the catalysts with a higher activity achieved for the catalysts coated using the bimetallic oxides. This was likely due to the increase in the specific surface area of the catalyst, which promoted the efficiency in the contact area of ethanol and the active sites, leading to some kind of synergy between the support catalyst and the metal oxides [34]. However, when excessive metal oxides were covered on the surface of the support catalyst, the activity of the catalysts decreased. This may be attributed to the partial bonding generated by the metal oxides on the acidity sites of catalysts by blocking the zeolite pores and, consequently, leading to the decrease in ethanol conversion. In addition, there existed diffusion restrictions associated with narrow pore size when metal contents further increased, and, as a result, the production of ethylene decreased by the reduction in the effective reaction area. Though the introduction of $\mathrm{Cr}$ and Co has shown shifts to the acid sites that have improved catalytic performance, the influence of pore size is still the dominating parameter [6].

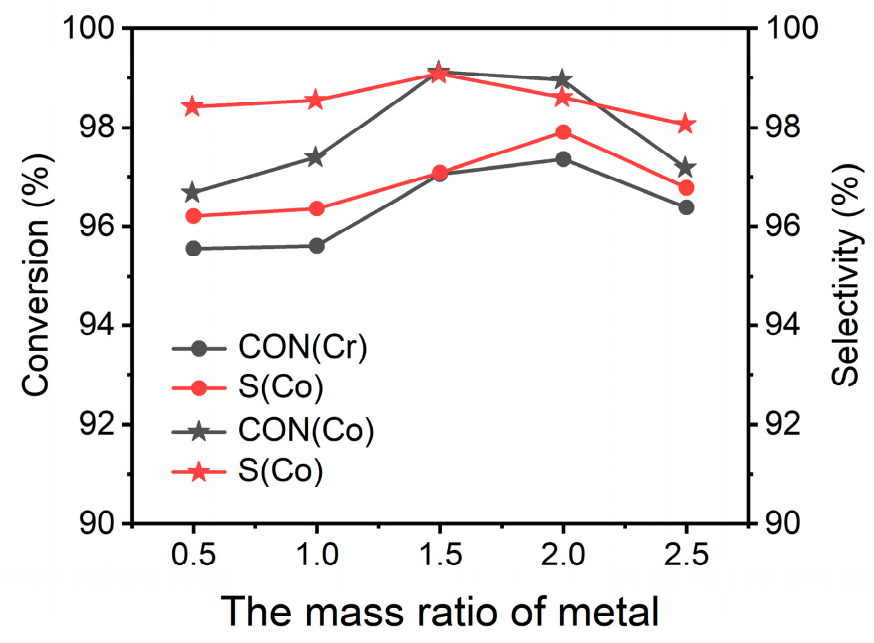

Figure 9. Effect of loading amount on the catalytic activity of modified SAPO-34 catalysts at a reaction temperature of $400{ }^{\circ} \mathrm{C}$ and WHSV of $3.5 \mathrm{~h}^{-1}$.

The reaction temperature plays a key role in ethanol conversion and ethylene selectivity. The prepared catalysts in the present study were tested at different temperatures at a WHSV of $3.5 \mathrm{~h}^{-1}$ and $0.5 \mathrm{~g}$ catalyst, and the results are shown in Figure 10. The ethanol conversion and ethylene selectivity of the catalysts demonstrated an increase with the rise in reaction temperature and performed best when the reaction temperature was $400{ }^{\circ} \mathrm{C}$. In the case of the $\mathrm{Cr} / \mathrm{SAPO}-34$ catalyst, the optimum ethanol conversion and ethylene selectivity was determined as $97.6 \%$ and $98.2 \%$, while that of the Co-Cr/SAPO-34 catalyst performed was obtained as $99.3 \%$ and $99.4 \%$, respectively. The evaluation of the ethanol conversion and ethylene selectivity showed an initial increasing trend followed by stabilization with a temperature increase. The pathway of ethanol dehydration to ethylene is considered an endothermic reaction, as shown in Equation (1), and the testing result confirms the existence of this 
endothermic reaction. This may have been attributed to the existence of intra- and inter-molecular dehydration in the conversion process of ethanol to ethylene. By producing carbonium ions at a lower reaction temperature, the existence of these stable carbonium ions combined with the ethanol molecules led to the production of diethyl ether via inter-molecular dehydration. At a higher reaction temperature, ethylene was obtained by the intra-molecular dehydration of ethanol via consumption of a large amount of energy to break the $\beta-\mathrm{H}$ bonds in carbonium ions, thereby reducing the lifespan of these ions, which favors the progress of the elimination reaction $[6,8,35,36]$. This process is shown in Figure 11. In addition, when the temperature is high, the $\mathrm{OH}$ group removal of the molecular sieve can be strengthened and the protonic acidity can be increased, thus causing better catalytic activity at higher temperature. Therefore, based on the evaluations in this study, higher temperatures are considered more conducive for ethylene formation, but with a further rise in temperature above the determined value in the study, the adsorption amount of ethyl ether on the catalyst becomes saturated and the reaction is produced in situ, which requires the tendency of ethanol conversion and ethylene selectivity to be stable.

$$
\mathrm{C}_{2} \mathrm{H}_{5} \mathrm{OH} \rightarrow \mathrm{C}_{2} \mathrm{H}_{4}+\mathrm{H}_{2} \mathrm{O} \rightarrow(\Delta \mathrm{H}=+44.9 \mathrm{~kJ} / \mathrm{mol})
$$

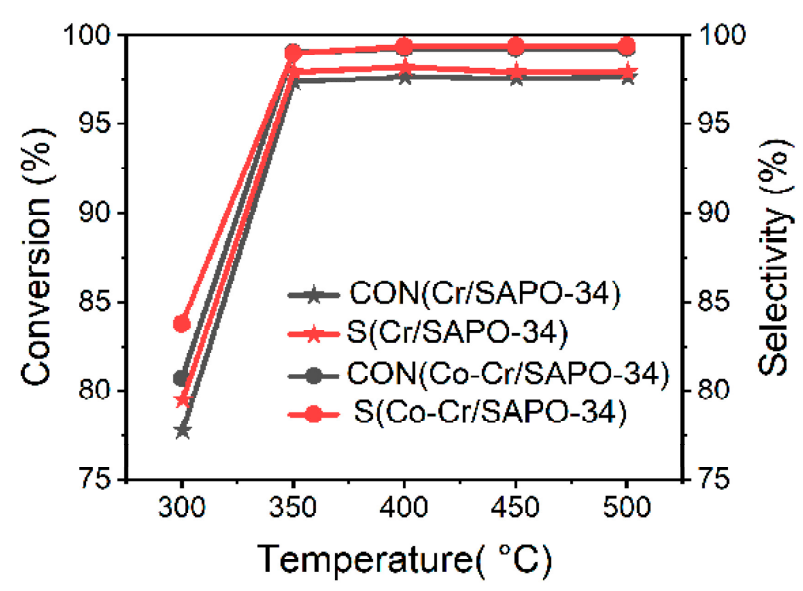

Figure 10. Performance of catalysts at different temperatures for $\mathrm{Cr} / \mathrm{SAPO}-34$ and Co-Cr/SAPO-34.<smiles>CC(C)=C(C)CCCC(C)(C)C(C)(C)O</smiles>

Figure 11. Elimination reaction diagram of intra-molecular dehydration of ethanol.

The ethanol conversion and ethylene selectivity at different WSHVs over $\mathrm{Cr} / \mathrm{SAPO}-34$ and Co-Cr/SAPO-34 catalysts are plotted in Figure 12. Evidently, the catalytic activity showed an initial stable tendency and then decreased with the increase in WHSV at a reaction temperature of $400{ }^{\circ} \mathrm{C}$ and a $0.5 \mathrm{~g}$ catalyst. At lower WHSV, there exists sufficient contact time between the raw material reactants and the catalysts, leading to a complete reaction feedstock to form ethylene [37]. On the other hand, an increase in WHSV leads to a shorter residence time of ethanol in the catalyst bed, which reduces reaction at the activity sites of catalysts. This generates an incomplete conversion of ethanol, leading to the formation of by-products like diethyl ether. Hence, for optimum results in this research, WHSV $3.5 \mathrm{~h}^{-1}$ was determined as the best value for subsequent experiments due to the cost of industrial production. 


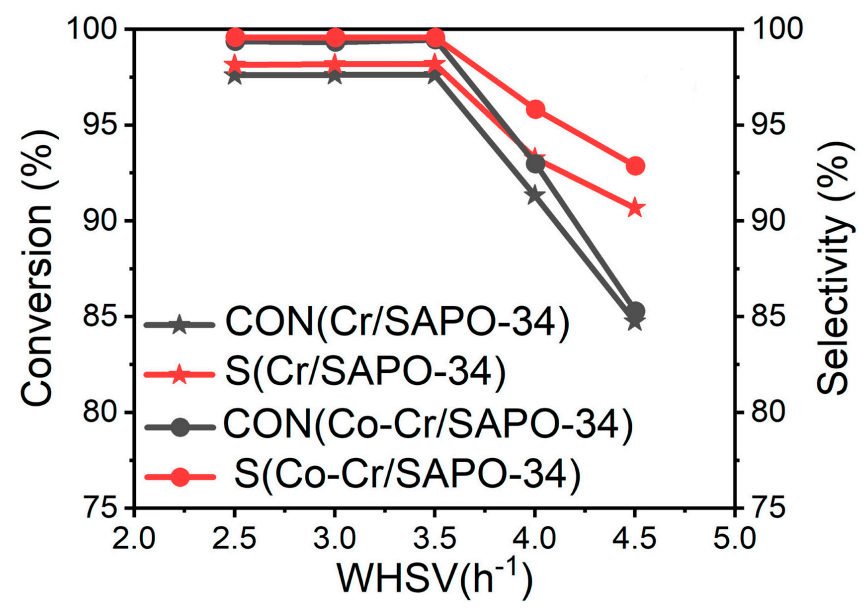

Figure 12. Performance of catalysts at different WHSVs for Cr/SAPO-34 and Co-Cr/SAPO-34.

The stability of the different catalysts was investigated at different reaction time intervals, as shown in Figure 13. The other reaction conditions of the $0.5 \mathrm{~g}$ catalyst: Temperature of $400{ }^{\circ} \mathrm{C}$ and WHSV of $3.5 \mathrm{~h}^{-1}$ were kept constant. As can be seen in Figure 13, the catalytic activity (ethanol conversion and ethylene selectivity) of $\mathrm{Cr} / \mathrm{SAPO}-34$ remained stable within the first $400 \mathrm{~min}$, and after this point, any further increase in reaction time resulted in a decrease in catalytic activity. This was primarily due to the deposition of more coke formed, which covered the active sites and partial channels as a function of increasing time. This decreased the catalytic activity of catalysts and affected the mass transfer rate of the feedstock and products. As expected, the excellent catalytic performance (ethanol conversion and ethylene selectivity $>98 \%$ ) of the $\mathrm{Co}-\mathrm{Cr} / \mathrm{SAPO}-34$ catalyst occurred during the last $600 \mathrm{~min}$. The longer lifespan of the $\mathrm{Co}-\mathrm{Cr} / \mathrm{SAPO}-34$ catalyst was mainly attributed to the synergistic effect between metal components and SAPO-34. It is generally believed that when the size of the cage contained in the molecular sieve is larger than the pore size of the channel, it will lead to carbon deposition inside the catalysts; however, the size of the CHA cage is $1.1 \mathrm{~nm} \times 0.65 \mathrm{~nm}$; each cage is connected to the others by six eight-membered rings on its side; the aperture of the eight-membered-rings channel is $0.38 \mathrm{~nm}$; and in ethanol conversion reactions, this narrow orifice allows only $C_{1}-C_{3}$ hydrocarbon molecules and normal hydrocarbon molecules to move freely in and out of the orifice, inhibiting the generation of isomeric hydrocarbons and aromatic hydrocarbons, thus improving the selectivity of ethylene. However, due to its small orifice and easy carbon deposition, the catalyst was rapidly deactivated, but the catalytic reaction performance was improved by means of adjusting the acidity, the selectivity of ethylene was improved, and the deactivation caused by carbon deposition was delayed. In addition, when the crystalline grain dispersion increased, the sensitivity to poison would be reduced. It can be concluded that the doping of the bimetallic oxides increased the reactive activity and extended the lifespan of the catalysts. By comparing SAPO-34 for ethanol dehydration in the

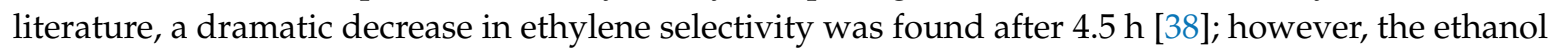
conversion and the ethylene selectivity of the Co-Cr/SAPO-34 catalyst in this work remained stable at $600 \mathrm{~min}$. Accordingly, the Co-Cr/SAPO-34 catalyst synthesized in our study might show promising potential as a good catalyst for the conversion of ethanol to ethylene. 


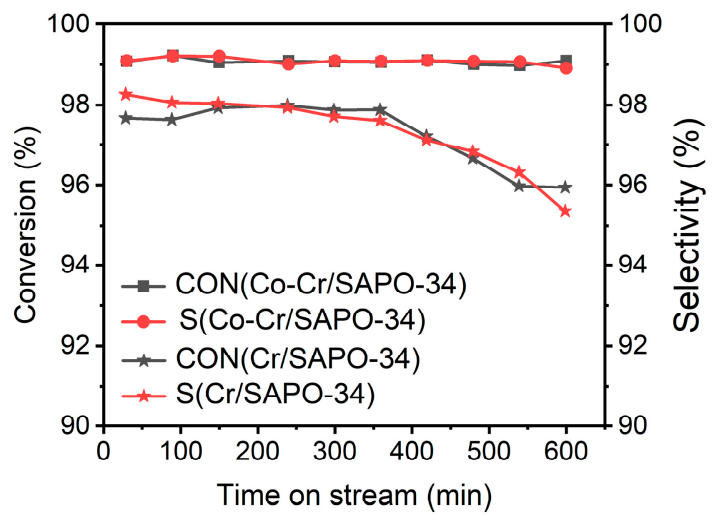

Figure 13. Performance of catalysts at different reaction times for $\mathrm{Cr} / \mathrm{SAPO}-34$ and Co-Cr/SAPO-34.

Catalytic testing of ethanol was performed and the resulting samples of $\mathrm{Cr} / \mathrm{SAPO}-34$ and $\mathrm{Co}-\mathrm{Cr} / \mathrm{SAPO}-34$ showed excellent catalytic performance as compared in Figure 14. In essence, the $\mathrm{Cr} / \mathrm{SAPO}-34$ and $\mathrm{Co}-\mathrm{Cr} / \mathrm{SAPO}-34$ showed higher efficiency than the SAPO-34 support (ethanol conversion of $92.3 \%$ and ethylene selectivity of $51.8 \%$ ). Therefore, the addition of metal components was demonstrated to be beneficial for the production of ethylene. The high conversion of the modified SAPO-34 catalysts may be due to relative hydrogen-deficient species deposited in the $\mathrm{CHA}$ cage, which are the primary reaction centers for light olefin production. This showed that the conversion of ethanol and the selectivity of ethylene increased in the following order: SAPO-34 $<\mathrm{Cr} / \mathrm{SAPO}-34<\mathrm{Co}-\mathrm{Cr} / \mathrm{SAPO}-34$, depicting that $\mathrm{Co}-\mathrm{Cr} / \mathrm{SAPO}-34$ was the most suitable catalyst for the dehydration of ethanol to ethylene in this work. In Table 3, the catalytic performance of various catalysts for ethanol dehydration to ethylene is summarized, and it can be seen that the catalytic activity of the modified SAPO-34 catalyst in this study exhibited higher catalytic activity than most catalysts in previous studies. Due to the suitable pore structure and moderate acid-base characteristics, it can be seen that the effect of cobalt and chromium metal loading on SAPO-34 was significantly better than that on HZSM-5 in the dehydration of ethanol. Compared to Mn/SAPO-34, its catalytic performance was not significantly improved, and interestingly, within $600 \mathrm{~min}$ of the reaction time, Co-Cr/SAPO-34 in this work still showed stable catalytic performance. In addition, the ethanol conversion and ethylene selectivity remained at about $99 \%$, but the ethylene selectivity showed a decreasing trend in the literature [6], indicating that the Co-Cr/SAPO-34 in this work showed relatively stable catalytic performance. Moreover, it was found that the bimetal-supported zeolite catalyst showed better catalytic activity than the single metal-supported catalyst, and even though with little improvement, the bimetal-supported catalyst is still comparable. Thus, the Co-Cr/SAPO-34 catalyst had considerable potential to be developed for dehydration of ethanol to ethylene.

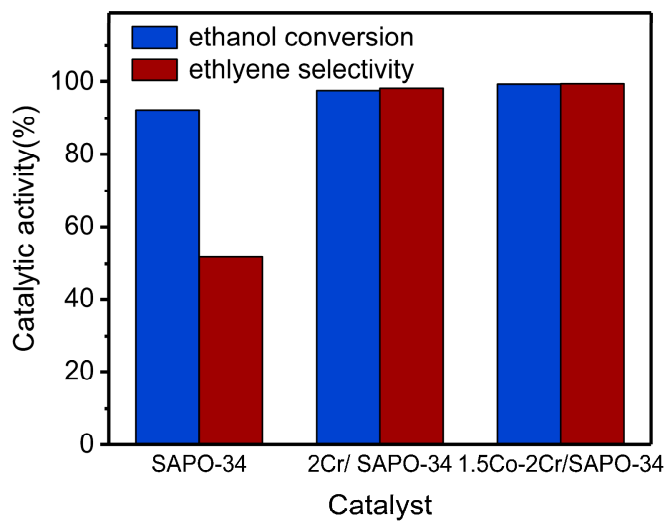

Figure 14. Comparison of catalytic activity of the different prepared catalysts at temperature of $400{ }^{\circ} \mathrm{C}$ and WHSV of $3.5 \mathrm{~h}^{-1}$. 
Table 3. Comparison of catalysts for ethylene dehydration and their catalytic ability.

\begin{tabular}{ccccc}
\hline Catalyst & Reaction Temperature $\left({ }^{\circ} \mathbf{C}\right)$ & Ethanol Conversion (\%) & Ethylene Selectivity (\%) & Reference \\
\hline HZSM-5 & 400 & 99 & 10 & {$[39]$} \\
Co/HZSM-5 & 400 & 94.82 & 76.16 & {$[40]$} \\
Cr/HZSM-5 & 400 & 93.85 & 23.81 & {$[40]$} \\
SAPO-34@ZSM-5 & 400 & 84.5 & 65 & {$[38]$} \\
Mn/SAPO-34 & 340 & 99.35 & 98.44 & {$[6]$} \\
SAPO-34 & 400 & 92.3 & 51.8 & This work \\
Cr/SAPO-34 & 400 & 97.6 & 98.2 & This work \\
Co-Cr/SAPO-34 & 400 & 99.3 & 99.4 & This work \\
\hline
\end{tabular}

The compositions of soluble carbon deposit attached to $\mathrm{Co}-\mathrm{Cr} / \mathrm{SAPO}-34$ and liquid products obtained in the hydration of ethanol at optimum conditions in $600 \mathrm{~min}$ are shown in Tables 4 and 5 respectively. Combined with the previous reports, the possible reaction path of ethanol to ethylene was deduced, as shown in the Figure 15. Ethanol was converted to ethylene by intramolecular dehydration, or ethanol was dehydrated by intermolecule dehydration to form ether and then converted to ethylene. Ethanol can be converted to $\mathrm{C}_{3} \mathrm{H}_{6}$ by oligomerization between $\mathrm{C}_{2} \mathrm{H}_{4}$ and carbene species, and converted to $\mathrm{C}_{4} \mathrm{H}_{8}$ by dimerization. Ethylene can also be polymerized to form long-chain alkanes [41,42]; the long-chain paraffins (undecane, 4-methyl-, hexadecane, etc.) in the product proved this speculation. In addition, the generated alkanes subsequently produced cyclic aromatic hydrocarbons and aromatic compounds via cyclization, dehydrogenation, and aromatization reactions, and the presence of various large aromatic compounds in liquid products and carbonaceous components also confirmed this speculation. Interestingly, it was obviously observed in Table 4 that there were significantly more long-chain alkanes than aromatic compounds, and the carbonaceous species formed using the modified SAPO-34 catalyst were mainly composed of long-chain alkanes rich in hydrogen, different from the aromatic species coked in/on ZSM-5 and consistent with the reports in the literature [43].

Table 4. Components of soluble coke formed from catalytic reaction of ethanol.

\begin{tabular}{|c|c|c|c|c|c|}
\hline NO. & $\begin{array}{c}\text { RT } \\
\text { (min) }\end{array}$ & Name of Compound & Molecular Formula & Structural Formula & $\begin{array}{c}\text { Similarity } \\
(\%)\end{array}$ \\
\hline 1 & 12.017 & Decane, 2,3,5-trimethyl- & $\mathrm{C}_{13} \mathrm{H}_{28}$ & & 72 \\
\hline 2 & 12.778 & Undecane, 4-methyl- & $\mathrm{C}_{12} \mathrm{H}_{26}$ & & 68 \\
\hline 3 & 14.406 & Decane, 2,4,6-trimethyl- & $\mathrm{C}_{13} \mathrm{H}_{28}$ & & 47 \\
\hline 4 & 14.65 & Benzaldehyde, 3,5-dimethyl- & $\mathrm{C}_{9} \mathrm{H}_{10} \mathrm{O}$ & & 95 \\
\hline 5 & 15.064 & Octane, 2,4,6-trimethyl- & $\mathrm{C}_{11} \mathrm{H}_{24}$ & & 53 \\
\hline 6 & 15.271 & Undecane, 2,4-dimethyl- & $\mathrm{C}_{13} \mathrm{H}_{28}$ & & 59 \\
\hline 7 & 15.509 & Hexadecane & $\mathrm{C}_{16} \mathrm{H}_{34}$ & & 72 \\
\hline 8 & 18.252 & Dihydrocoumarin, 4,4,5,7,8-pentamethyl & $\mathrm{C}_{13} \mathrm{H}_{16} \mathrm{O}_{2}$ & & 64 \\
\hline 9 & 18.575 & 2,4-Di-tert-butylphenol & $\mathrm{C}_{14} \mathrm{H}_{22} \mathrm{O}$ & & 96 \\
\hline 10 & 18.794 & Dodecane, 3-methyl- & $\mathrm{C}_{13} \mathrm{H}_{28}$ & & 72 \\
\hline 11 & 20.708 & Heptadecane & $\mathrm{C}_{17} \mathrm{H}_{36}$ & & 97 \\
\hline 12 & 22.75 & Octadecane & $\mathrm{C}_{18} \mathrm{H}_{38}$ & & 93 \\
\hline 13 & 25.713 & Cyclohexadecane & $\mathrm{C}_{16} \mathrm{H}_{32}$ & & 93 \\
\hline 14 & 27.913 & Phenol, 2,2'-methylenebis(6-(1,1-dimethylethyl)-4-methyl- & $\mathrm{C}_{21} \mathrm{H}_{28} \mathrm{O}_{2}$ & & 91 \\
\hline
\end{tabular}


Table 5. Compounds of liquid products from catalytic reaction of ethanol over Co-Cr/SAPO-34.

\begin{tabular}{|c|c|c|c|c|c|}
\hline NO. & $\begin{array}{c}\text { RT } \\
\text { (min) }\end{array}$ & Name of Compound & Molecular Formula & Structural Formula & $\begin{array}{c}\text { Similarity } \\
(\%)\end{array}$ \\
\hline 1 & 3.361 & Butanoic acid, 2-methylpropyl ester & $\mathrm{C}_{8} \mathrm{H}_{16} \mathrm{O}_{2}$ & & 72 \\
\hline 2 & 6.726 & Thymol, TMS derivative & $\mathrm{C}_{10} \mathrm{H}_{14} \mathrm{O}$ & & 50 \\
\hline 3 & 18.362 & 2,6-Dihydroxyacetophenone, 2TMS derivative & $\mathrm{C}_{8} \mathrm{H}_{8} \mathrm{O}_{3}$ & & 50 \\
\hline 4 & 22.348 & Cyclopentadecanone, 2-hydroxy- & $\mathrm{C}_{15} \mathrm{H}_{28} \mathrm{O}_{2}$ & & 97 \\
\hline 5 & 27.895 & Phenol, 2,2'-methylenebis(6-(1,1-dimethylethyl)-4-methyl- & $\mathrm{C}_{23} \mathrm{H}_{32} \mathrm{O}_{2}$ & & 90 \\
\hline
\end{tabular}

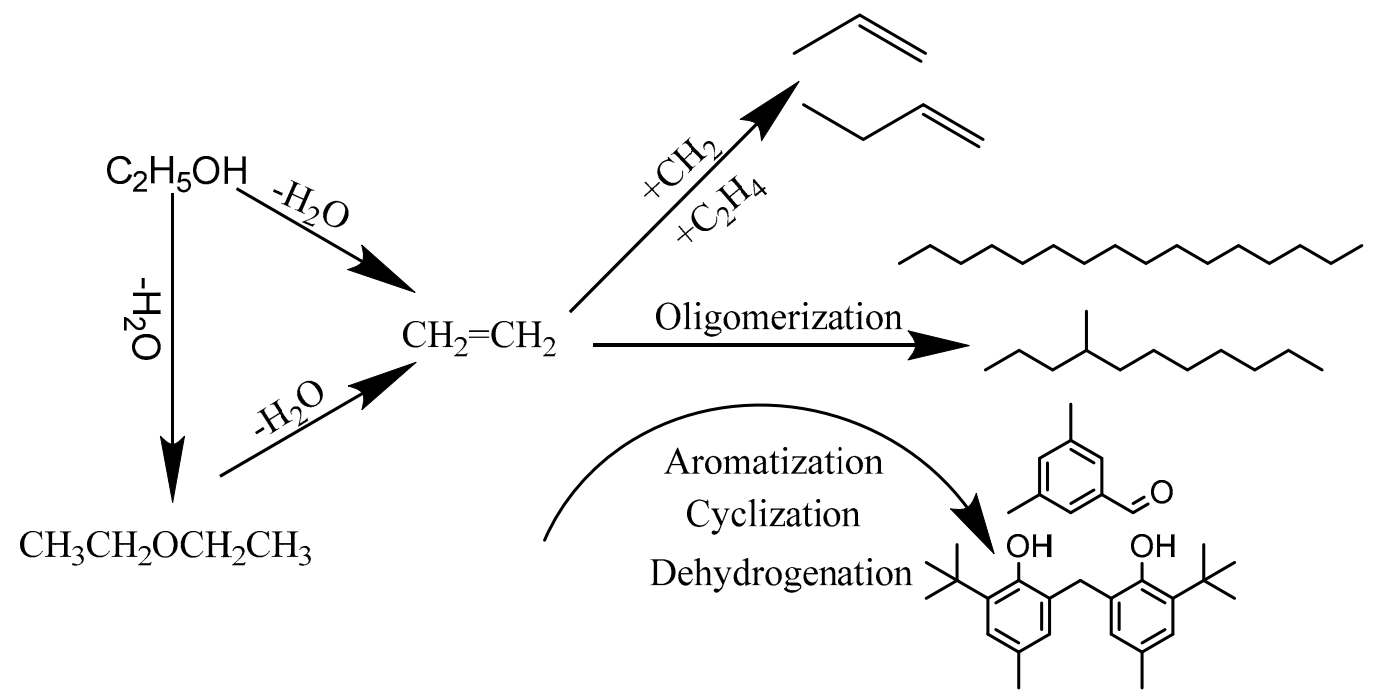

Figure 15. Postulated reaction pathway for catalytic reaction of ethanol.

\section{Materials and Methods}

\subsection{Material}

Tetraethylammonium hydroxide (TEAOH, 25\%, Xilong Scientific Co., Ltd., Gunagdong, China), aluminum isopropoxide (98\%, Macklin Chemical Reagent, Shanghai, China), tetraethyl orthosilicate (TEOS, Xilong Scientific Co., Ltd., Guangdong, China), phosphoric acid $\left(\mathrm{H}_{3} \mathrm{PO}_{4}, 85 \%\right.$, Xilong Scientific Co., Ltd.), chromic nitrate nonahydrate $\left(\mathrm{Cr}\left(\mathrm{NO}_{3}\right)_{3} \cdot 9 \mathrm{H}_{2} \mathrm{O}\right.$, Macklin Chemical Reagent), and cobaltous nitrate hexahydrate $\left(\mathrm{Co}\left(\mathrm{NO}_{3}\right)_{2} \cdot 6 \mathrm{H}_{2} \mathrm{O}\right.$, Macklin Chemical Reagent) were used as received.

\subsection{Catalyst Preparation}

The metal oxide-modified silicoaluminophosphate catalyst was prepared following a two-step procedure, as schematically illustrated in Figure 16.

The first step (a) involves the synthesis of the SAPO-34 support. TEOS, aluminum isopropoxide, and $\mathrm{H}_{3} \mathrm{PO}_{4}$ were used as $\mathrm{Si}$, $\mathrm{Al}$, and $\mathrm{P}$ sources, respectively. TEAOH was used as the structure directing agent. In brief, a precursor SAPO-34 gel was prepared with a molar ratio of 1.0 $\mathrm{Al}_{2} \mathrm{O}_{3}: 1.0 \mathrm{P}_{2} \mathrm{O}_{5}: 0.5 \mathrm{SiO}_{2}: 1.0 \mathrm{TEAOH}: 50 \mathrm{H}_{2} \mathrm{O}$. The gel mixture was transferred into a Teflon-lined stainless steel, and heated at $180{ }^{\circ} \mathrm{C}$ for $48 \mathrm{~h}$. The obtained gel was filtrated, washed, and dried at $120{ }^{\circ} \mathrm{C}$ for $12 \mathrm{~h}$. The final product was then calcined at $550{ }^{\circ} \mathrm{C}$ for $12 \mathrm{~h}$. 
(a) Obtained the shaped SAPO-34 catalyst

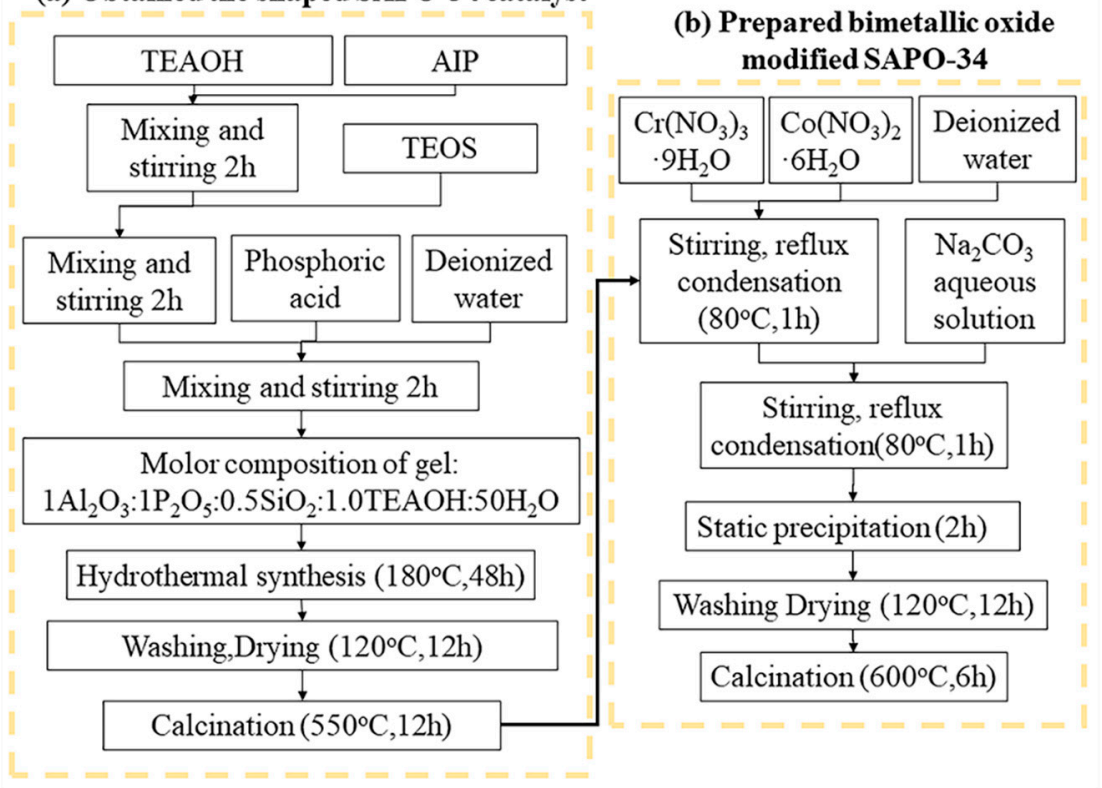

Figure 16. Schematic flow chart of synthetic pathway of shaped SAPO-34 support and preparation of modified SAPO-34 catalysts.

In the second step (b), the Cr-based SAPO-34 catalysts were prepared via an impregnation method. In brief, the support was first impregnated with an aqueous solution of $\mathrm{Cr}\left(\mathrm{NO}_{3}\right)_{3} \cdot 9 \mathrm{H}_{2} \mathrm{O}$ at $80{ }^{\circ} \mathrm{C}$, to ensure $0.5-2.5 \mathrm{wt} \% \mathrm{Cr}$ in the final catalyst. The suspension mixture was then stirred under continuous refluxing, and a certain amount of $\mathrm{NaCO}_{3}$ solution was added. The final obtained mixture was allowed to stand before being aged, filtered, washed, dried, and calcined at $550{ }^{\circ} \mathrm{C}$ for $5 \mathrm{~h}$. Subsequently, the resulting catalyst was sieved through a 20-40 mesh-size sieve and the resulting particles were collected, denoted as $x \mathrm{Cr} / \mathrm{SAPO}-34$ (where $x$ represents the weight ratio of the metal). In order to prepare the Co-Cr/SAPO-34 catalysts, the solutions of $\mathrm{Cr}\left(\mathrm{NO}_{3}\right)_{3} \cdot 9 \mathrm{H}_{2} \mathrm{O}$ and $\mathrm{Co}\left(\mathrm{NO}_{3}\right)_{2} \cdot 6 \mathrm{H}_{2} \mathrm{O}$ of different varying concentrations were loaded onto the resultant SAPO-34 support. The mass fraction of $\mathrm{Cr}_{2} \mathrm{O}_{3}$ and $\mathrm{CoO}$ used was $2 \mathrm{wt} \%$ and $0.5-2.5 \mathrm{wt} \%$ in the catalysts, respectively. The next steps were similar to those described above. The final prepared samples were denoted as yCo-2Cr/SAPO-34 (where y represents the weight ratio of the metal).

\subsection{Characterization of Catalysts}

The crystalline phase composition of the samples was determined by X-ray diffraction (XRD, Rigaku SmartLab, Agilent, Santa Clara, CA, USA) with $\mathrm{Cu} \mathrm{K} \alpha$ monochromatized radiation $(\lambda=0.154 \mathrm{~nm})$. The tube voltage was $40 \mathrm{kV}$, and the samples were scanned at a rate of $8.0^{\circ} / \mathrm{min}$ in the range $2 \theta=5-60^{\circ}$.

The morphology of synthesized catalysts was investigated using scanning electron microscopy (SEM), with an HITACHI E-1045 analyzer. In order to improve the conductivity and resolution of images, a thin layer of gold was covered on the samples.

The chemical compositions of the synthesized samples were analyzed by an energy-dispersive X-ray analyzer (EDX, Bruker XFlash 6|60, Billerica, MA, USA).

Fourier-transform infrared (FT-IR) spectra were collected by a Thermo Trace 1310-Nicolet IS50 spectrometer (Nicolet 6700, Thermo Fisher Scientific, Shanghai, China) in order to address surface functional groups. The FT-IR resolution and number of scans were set as $4 \mathrm{~cm}^{-1}$ and 40 scans per spectrum, respectively. The FT-IR spectra were recorded in the range of $4000-500 \mathrm{~cm}^{-1}$.

The acidity of the catalysts was analyzed by an ammonia temperature-programmed desorption $\left(\mathrm{NH}_{3}-\mathrm{TPD}\right)$ experiment, which is a quartz tube reactor equipped with a residual gas analyzer (RGA 200, 
Agilent). Before the adsorption experiment, $0.2 \mathrm{~g}$ of catalyst was pretreated in a He stream at $300{ }^{\circ} \mathrm{C}$ for $1 \mathrm{~h}$, and then cooled to $110^{\circ} \mathrm{C} . \mathrm{NH}_{3}$ was introduced under the He stream until the adsorption reached saturation, and the physically adsorbed $\mathrm{NH}_{3}$ was then removed by purging with a He stream for $3 \mathrm{~h}$. The sample was heated to $800{ }^{\circ} \mathrm{C}$ at a heating rate of $10^{\circ} \mathrm{C} / \mathrm{min}$. The distribution of weak acid and strong acid $\left(100-275^{\circ} \mathrm{C}, 275-600^{\circ} \mathrm{C}\right)$ was calculated from the peak area of the Gaussian fitting of the $\mathrm{NH}_{3}$-TPD profiles. Desorbed $\mathrm{NH}_{3}$ was absorbed in $100 \mathrm{~mL} \mathrm{HCl}$ solution $(0.01 \mathrm{~mol} / \mathrm{L}), \mathrm{NaOH}$ solution $(0.01 \mathrm{~mol} / \mathrm{L})$ was used to titrate the residual $\mathrm{HCl}$ solution, and the total acidity of the catalysts was calculated by the following equation:

$$
\text { Total acidty }=\frac{V_{\mathrm{HCl}}-V_{\mathrm{NaOH}}}{m_{\mathrm{c}}} \times 0.01
$$

where $V_{\mathrm{HCl}}$ is the volume of the $\mathrm{HCl}$ solution used $(100 \mathrm{~mL}), V_{\mathrm{NaOH}}$ is the volume of the $\mathrm{NaOH}$ solution consumed $(\mathrm{mL})$, the concentration of the $\mathrm{NaOH}$ and $\mathrm{HCl}$ solution is $0.01 \mathrm{~mol} / \mathrm{L}$, and $m_{\mathcal{C}}$ is the mass of catalyst (g).

The Brunauer-Emmett-Teller $(\mathrm{BET})$ surface area $\left(\mathrm{S}_{\mathrm{BET}}\right)$, total pore volume $\left(\mathrm{V}_{\text {Total }}\right)$, and average pore diameter $\left(\mathrm{D}_{\text {pore }}\right)$ of the catalysts were measured using a NOVA 2200e-type adsorption apparatus from Quantachrome, USA. Prior to testing, the samples were degassed under vacuum at $200{ }^{\circ} \mathrm{C}$ for $5 \mathrm{~h}$ in a stream of nitrogen. The relative pressure $(\mathrm{P} / \mathrm{Po})$ at which the pore volume was measured was 0.99 .

The amount of coke deposition in the reaction of ethanol to ethylene was calculated by a TG209F3 Tarsu thermogravimetric instrument (NETZSH, GER, Selb, Germany). The dried catalysts (0.01 g) were placed in the crucible. The sample was heated at a temperature-programmed rate of $20^{\circ} \mathrm{C} / \mathrm{min}$ to $800^{\circ} \mathrm{C}$ under dry air flow. The TGA curve records the mass change of a sample with the increase in temperature.

\subsection{Catalytic Reaction}

The catalytic performance of the prepared catalysts was evaluated via catalytic cracking of ethanol in a fixed bed reactor. The system was basically composed of a quartz tube reactor (inner diameter: $20 \mathrm{~mm}$ and length: $380 \mathrm{~mm}$ ), a condenser, a syringe pump, and an electric heating sleeve. For a typical run, the sample $(0.5 \mathrm{~g})$ was loaded into the reactor and heated to $600{ }^{\circ} \mathrm{C}$ under $\mathrm{N}_{2}$ atmosphere at a flow rate $40 \mathrm{~mL} / \mathrm{min}$. The feedstock was then injected into the reactor using a micro-metering pump, the temperature was set, and the catalytic activity was evaluated at different space velocities. For each test, the ethanol was replaced with fresh feed to ensure that the reactant feed concentration was constant. Once the flowing-out from the reactor was reached, the products were cooled and the liquid products were collected through a constant-temperature circulating condenser, while the gas products were collected via a gas-collecting bag and analyzed using GC by referring to the method as described in the study [27]. Liquid products were analyzed by GC-MS (Agilent 7890B) equipped with an HP-5ms capillary column $(30 \mathrm{~m} \times 0.25 \mathrm{~mm} \times 0.25 \mu \mathrm{m}$, Agilent $\mathrm{J \& W})$. The temperature of the oven was set at $40^{\circ} \mathrm{C}$, held for $5 \mathrm{~min}$, increased to $250^{\circ} \mathrm{C}$ with $10^{\circ} \mathrm{C} / \mathrm{min}$, and held for $2 \mathrm{~min}$. The carrier gas was helium and the flow rate was $1.2 \mathrm{~mL} / \mathrm{min}$. The injector and detector temperature were both $280^{\circ} \mathrm{C}$. Each test was repeated three times, and the average data were adopted.

The conversion $(C O N)$ of ethanol and the selectivity $(S)$ of ethylene were used to evaluate the efficiency of the catalyst in the process of ethanol catalytic dehydration. $C O N$ and $S$ were then calculated using the mathematical equations below:

$$
\begin{gathered}
\operatorname{CON}(\%)=\frac{m_{1}}{m_{0}} \times 100 \% \\
S(\%)=\frac{m_{2}}{m_{1}} \times 100 \%
\end{gathered}
$$

where $m_{0}$ is the mass of the feedstock, $m_{1}$ is the mass of the reacted ethanol, and $m_{2}$ is the mass of the ethanol that converted to ethylene $(\mathrm{g})$. 
Carbon composition analysis was as follows: $0.5 \mathrm{~g}$ of catalysts used in the ethanol dehydration reaction were dispersed in $2 \mathrm{~mL}$ dichloromethane for $12 \mathrm{~h}$, and the composition of the soluble coke dissolved in dichloromethane was then analyzed by GC-MS. The analytical conditions were consistent with those of liquid products.

\section{Conclusions}

The metal-modified SAPO-34 catalysts were successfully synthesized via the impregnation precipitation method, and the optimal reaction conditions for the conversion of ethanol to ethylene were extensively studied in this work. XRD, SEM, EDX, and BET analysis indicated that the investigated metal oxides were successfully coated on the surface of the zeolites. Compared to the SAPO-34 support, the specific surface area of the investigated modified catalysts increased, while the CHA structure of the SAPO-34 zeolite remained stable. In addition, evaluating the acidity strength showed that weak acid was weakened in the presence of the catalysts while the acidity of the strong acid was enhanced. The conversion of ethanol and the selectivity of ethylene were determined to increase in the order of SAPO-34 $<\mathrm{Cr} / \mathrm{SAPO}-34<\mathrm{Co}-\mathrm{Cr} / \mathrm{SAPO}-34$. The results also give a reference for the application of bimetal-modified catalysts in the production of ethylene from ethanol. Moreover, the present study determined that the per-pass conversion of ethanol was $99.3 \%$ and the selectivity of ethylene was $99.4 \%$ for the $\mathrm{Co}-\mathrm{Cr} / \mathrm{SAPO}-34$ catalyst. Although its catalytic performance was slightly improved compared to that of the Cr/SAPO-34 catalyst, its lifetime was obviously prolonged, which could still be maintained for up to $600 \mathrm{~min}$ of reaction time. Conditional optimization experiments showed that the prepared modified catalysts possessed better performance when the reaction conditions were kept constant at an amount of catalyst of $0.5 \mathrm{~g}$, reaction temperature of $400{ }^{\circ} \mathrm{C}$, and weight hour velocity of $3.5 \mathrm{~h}^{-1}$. The Co-Cr/SAPO-34 sample exhibited the best catalytic performance, as well as increased ethylene selectivity compared to most of the other catalysts. It is speculated that the Co-Cr/SAPO-34 has a long lifetime, as the catalyst showed relatively stable catalytic performance within the tested time on stream (600 $\mathrm{min}$ ). In addition, we also found that the carbonaceous components of the SAPO-34 catalyst were mainly long-chain alkanes rather than aromatic compounds. In other words, the Co-Cr/SAPO-34 catalyst not only has good catalytic performance but also has a longer lifetime in dehydration of ethanol than most catalysts in previous studies. The experimental data investigated in this study proved feasible and can be suitably applied in the production of ethylene using the Co-Cr/SAPO-34 catalyst.

Author Contributions: P.N. designed and performed the experiments, analyzed the data, and wrote the paper; X.R. and D.X. conceived the experiments; P.N. and X.R. carried out XRD, SEM, EDX, FT-IR, $\mathrm{NH}_{3}-\mathrm{TPD}, \mathrm{BET}$, and TGA analysis and interpreted the data; S.D. and Y.L. revised the manuscript; Z.W. and X.C. used the software to process the data. All authors have read and agreed to the published version of the manuscript.

Funding: This research was supported by the Guangxi Nature Science Foundation of China (-2018GXNSFAA281343) and the Dean Project of Guangxi Key Laboratory of Petrochemical Resource Processing and Process Intensification Technology (2019Z005).

Conflicts of Interest: The authors declare no conflict of interest.

\section{References}

1. Wu, C.Y.; Wu, H.S. Ethylene Formation from Ethanol Dehydration Using ZSM-5 Catalyst. ACS Omega 2017, 2, 4287-4296. [CrossRef] [PubMed]

2. Sedighi, M.; Ghasemi, M.; Sadeqzadeh, M.; Hadi, M. Thorough study of the effect of metal-incorporated SAPO-34 molecular sieves on catalytic performances in MTO process. Powder Technol. 2016, 291, 131-139. [CrossRef]

3. Keyvanloo, K.; Sedighi, M.; Towfighi, J. Genetic algorithm model development for prediction of main products in thermal cracking of naphtha: Comparison with kinetic modeling. Chem. Eng. J. 2012, 209, 255-262. [CrossRef]

4. Chen, J.Q.; Bozzano, A.; Glover, B.; Fuglerud, T.; Kvisle, S. Recent advancements in ethylene and propylene production using the UOP/Hydro MTO process. Catal. Today 2005, 106, 103-107. [CrossRef] 
5. Sedighi, M.; Keyvanloo, K.; Towfighi, J. Experimental study and optimization of heavy liquid hydrocarbon thermal cracking to light olefins by response surface methodology. Korean J. Chem. Eng. 2010, 27, 1170-1176. [CrossRef]

6. Chen, Y.; Wu, Y.; Tao, L.; Dai, B.; Yang, M.; Chen, Z.; Zhu, X. Dehydration reaction of bio-ethanol to ethylene over modified SAPO catalysts. J. Ind. Eng. Chem. 2010, 16, 717-722. [CrossRef]

7. Chen, B.; Lu, J.; Wu, L.; Chao, Z. Dehydration of bio-ethanol to ethylene over iron exchanged HZSM-5. Chin. J. Catal. 2016, 37, 1941-1948. [CrossRef]

8. Zhang, X.; Wang, R.; Yang, X.; Zhang, F. Comparison of four catalysts in the catalytic dehydration of ethanol to ethylene. Microporous Mesoporous Mater. 2008, 116, 210-215. [CrossRef]

9. Aghaei, E.; Haghighi, M.; Pazhohniya, Z.; Aghamohammadi, S. One-pot hydrothermal synthesis of nanostructured ZrAPSO-34 powder: Effect of Zr-loading on physicochemical properties and catalytic performance in conversion of methanol to ethylene and propylene. Microporous Mesoporous Mater. 2016, 226, 331-343. [CrossRef]

10. Izadbakhsh, A.; Farhadi, F.; Khorasheh, F.; Sahebdelfar, S.; Asadi, M.; Feng, Y.Z. Effect of SAPO-34's composition on its physico-chemical properties and deactivation in MTO process. Appl. Catal. Gen. 2009, 364, 48-56. [CrossRef]

11. Khoshbin, R.; Haghighi, M.; Asgari, N. Direct synthesis of dimethyl ether on the admixed nanocatalysts of $\mathrm{CuO}-\mathrm{ZnO}-\mathrm{Al}_{2} \mathrm{O}_{3}$ and $\mathrm{HNO}_{3}$-modified clinoptilolite at high pressures: Surface properties and catalytic performance. Mater. Res. Bull. 2013, 48, 767-777. [CrossRef]

12. Li, X.; Sun, M.; Rooke, J.C.; Chen, L.; Su, B.-L. Synthesis and applications of hierarchically porous catalysts. Chin. J. Catal. 2013, 34, 22-47. [CrossRef]

13. Olsbye, U.; Svelle, S.; Bjørgen, M.; Beato, P.; Janssens, T.V.W.; Joensen, F.; Bordiga, S.; Lillerud, K.P. Heterogeneous Catalysis Conversion of Methanol to Hydrocarbons: How Zeolite Cavity and Pore Size Controls Product Selectivity. Angew. Chem. Int. Ed. 2012, 51, 5810-5831. [CrossRef] [PubMed]

14. Zhong, J.; Han, J.; Wei, Y.; Xu, S.; Sun, T.; Guo, X.; Song, C.; Liu, Z. Enhancing ethylene selectivity in MTO reaction by incorporating metal species in the cavity of SAPO-34 catalysts. Chin. J. Catal. 2018, 39, 1821-1831. [CrossRef]

15. Inoue, M.; Dhupatemiya, P.; Phatanasri, S.; Tomoyuki, I. Synthesis course of the Ni-SAPO-34 catalyst for methanol-to-olefin conversion. Microporous Mesoporous Mater. 1999, 28, 19-24. [CrossRef]

16. Tian, S.; Ji, S.; Lü, D.; Bai, B.; Sun, Q. Preparation of modified Ce-SAPO-34 catalysts and their catalytic performances of methanol to olefins. J. Energy Chem. 2013, 22, 605-609. [CrossRef]

17. Kang, M. Methanol conversion on metal-incorporated SAPO-34s (MeAPSO-34s). J. Mol. Catal. Chem. 2000, 160, 437-444. [CrossRef]

18. Hotevar, S.; Levec, J. Acidity and catalytic activity of McAPSO-34 (Me = Co, Mn, Cr), SAPO-34, and H-ZSM-5 molecular sieves in methanol dehydration. J. Catal. 1992, 135, 518-532. [CrossRef]

19. Bjørgen, M.; Svelle, S.; Joensen, F.; Nerlov, J.; Kolboe, S.; Bonino, F.; Palumbo, L.; Bordiga, S.; Olsbye, U. Conversion of methanol to hydrocarbons over zeolite H-ZSM-5: On the origin of the olefinic species. J. Catal. 2007, 249, 195-207. [CrossRef]

20. Qian, Q.; Ruiz-Martínez, J.; Mokhtar, M.; Asiri, A.M.; Al-Thabaiti, S.A.; Basahel, S.N.; Weckhuysen, B.M. Single-catalyst particle spectroscopy of alcohol-to-olefins conversions: Comparison between SAPO-34 and SSZ-13. Catal. Today 2014, 226, 14-24. [CrossRef]

21. Talukdar, A.K.; Bhattacharyya, K.G.; Sivasanker, S. HZSM-5 catalysed conversion of aqueous ethanol to hydrocarbons. Appl. Catal. Gen. 1997, 148, 357-371. [CrossRef]

22. Galadima, A.; Muraza, O. Zeolite catalysts in upgrading of bioethanol to fuels range hydrocarbons: A review. J. Ind. Eng. Chem. 2015, 31, 1-14. [CrossRef]

23. Varzaneh, A.Z.; Towfighi, J.; Kootenaei, A.H.S.; Mohamadalizadeh, A. Effect of cerium and zirconium nanoparticles on the structure and catalytic performance of SAPO-34 in steam cracking of naphtha to light olefins. React. Kinet. Mech. Catal. 2015, 115, 719-740. [CrossRef]

24. Aghaei, E.; Haghighi, M. Hydrothermal synthesis of nanostructured Ce-SAPO-34: High-performance and long-lifetime catalyst with various ceria contents for methanol to light olefins conversion. Microporous Mesoporous Mater. 2018, 270, 227-240. [CrossRef]

25. Jongsomjit, B.; Goodwin, J.G. Co-support compound formation in $\mathrm{Co} / \mathrm{Al}_{2} \mathrm{O}_{3}$ catalysts: Effect of reduction gas containing CO. Catal. Today 2002, 77, 191-204. [CrossRef] 
26. Rafi-ud-din; Xuanhui, Q.; Ping, L.; Zhang, L.; Ahmad, M. Hydrogen Sorption Improvement of $\mathrm{LiAlH}_{4}$ Catalyzed by $\mathrm{Nb}_{2} \mathrm{O}_{5}$ and $\mathrm{Cr}_{2} \mathrm{O}_{3}$ Nanoparticles. J. Phys. Chem. C 2011, 115, 13088-13099. [CrossRef]

27. Li, F.; Ding, S.; Wang, Z.; Li, Z.; Li, L.; Gao, C.; Zhong, Z.; Lin, H.; Chen, C. Production of Light Olefins from Catalytic Cracking Bio-oil Model Compounds over $\mathrm{La}_{2} \mathrm{O}_{3}$-Modified ZSM-5 Zeolite. Energy Fuels 2018, 32, 5910-5922. [CrossRef]

28. Aghamohammadi, S.; Haghighi, M.; Charghand, M. Methanol conversion to light olefins over nanostructured CeAPSO-34 catalyst: Thermodynamic analysis of overall reactions and effect of template type on catalytic properties and performance. Mater. Res. Bull. 2014, 50, 462-475. [CrossRef]

29. Salmasi, M.; Fatemi, S.; Taheri Najafabadi, A. Improvement of light olefins selectivity and catalyst lifetime in MTO reaction; using $\mathrm{Ni}$ and Mg-modified SAPO-34 synthesized by combination of two templates. J. Ind. Eng. Chem. 2011, 17, 755-761. [CrossRef]

30. Yu, Y.; Xu, Y.; Cheng, D.; Chen, Y.; Chen, F.; Lu, X.; Huang, Y.; Ni, S. Transformation of syngas to light hydrocarbons over bifunctional $\mathrm{CuO}-\mathrm{ZnO} / \mathrm{SAPO}-34$ catalysts: The effect of preparation methods. Reac. Kinet. Mech. Cat. 2014, 112, 489-497. [CrossRef]

31. Kebin, C.; Zhen, Z.; Zhijian, T.; Sheng, H.; Lijun, Y.; Tianshu, L.; Bingchun, W.; Xiangbin, M.; Shanbin, G.; Mingwei, T.; et al. Hydroisomerization performance of platinum supported on ZSM-22/ZSM-23 intergrowth zeolite catalyst. Pet. Sci. 2012, 10, 242-250.

32. Wu, L.; Zhou, T.; Cui, Q.; Wang, H.; Hu, Y.; Huang, H. The Catalytic Dehydration of Bio-ethanol to Ethylene on SAPO-34 Catalysts. Pet. Sci. Technol. 2013, 31, 2414-2421. [CrossRef]

33. Akhoundzadeh, H.; Taghizadeh, M.; Sharifi Pajaie, H. Synthesis of highly selective and stable mesoporous $\mathrm{Ni}$-Ce/SAPO-34 nanocatalyst for methanol-to-olefin reaction: Role of polar aprotic N, N-dimethylformamide solvent. Particuology 2018, 40, 113-122. [CrossRef]

34. Nawaz, Z.; Tang, X.; Wang, Y.; Wei, F. Parametric Characterization and Influence of Tin on the Performance of Pt-Sn/SAPO-34 Catalyst for Selective Propane Dehydrogenation to Propylene. Ind. Eng. Chem. Res. 2010, 49, 1274-1280. [CrossRef]

35. Goetze, J.; Meirer, F.; Yarulina, I.; Gascon, J.; Kapteijn, F.; Ruiz-Martínez, J.; Weckhuysen, B.M. Insights into the Activity and Deactivation of the Methanol-to-Olefins Process over Different Small-Pore Zeolites as Studied with Operando UV-vis Spectroscopy. ACS Catal. 2017, 7, 4033-4046. [CrossRef]

36. Phung, T.K.; Busca, G. Diethyl ether cracking and ethanol dehydration: Acid catalysis and reaction paths. Chem. Eng. J. 2015, 272, 92-101. [CrossRef]

37. Montañez, M.K.; Molina, R.; Moreno, S. Nickel catalysts obtained from hydrotalcites by coprecipitation and urea hydrolysis for hydrogen production. Int. J. Hydrogen Energy 2014, 39, 8225-8237. [CrossRef]

38. Li, X.; Rezaei, F.; Ludlow, D.K.; Rownaghi, A.A. Synthesis of SAPO-34@ZSM-5 and SAPO-34@Silicalite-1 Core-Shell Zeolite Composites for Ethanol Dehydration. Ind. Eng. Chem. Res. 2018, 57, 1446-1453. [CrossRef]

39. Chaichana, E.; Wiwatthanodom, W.; Jongsomjit, B.; Li, H. Carbon-Based Catalyst from Pyrolysis of Waste Tire for Catalytic Ethanol Dehydration to Ethylene and Diethyl Ether. Int. J. Chem. Eng. 2019. [CrossRef]

40. Inaba, M.; Murata, K.; Saito, M.; Takahara, I. Ethanol conversion to aromatic hydrocarbons over several zeolite catalysts. React. Kinet. Catal. Lett. 2006, 88, 135-141. [CrossRef]

41. Sievers, C.; Liebert, J.S.; Stratmann, M.M.; Olindo, R.; Lercher, J.A. Comparison of zeolites LaX and LaY as catalysts for isobutane/2-butene alkylation. Appl. Catal. Gen. 2008, 336, 89-100. [CrossRef]

42. Xia, W.; Takahashi, A.; Nakamura, I.; Shimada, H.; Fujitani, T. Study of active sites on the MFI zeolite catalysts for the transformation of ethanol into propylene. J. Mol. Catal. Chem. 2010, 328, 114-118. [CrossRef]

43. Li, J.; Xiong, G.; Feng, Z.; Liu, Z.; Xin, Q.; Li, C. Coke formation during the methanol conversion to olefins in zeolites studied by UV Raman spectroscopy. Microporous Mesoporous Mater. 2000, 39, 275-280. [CrossRef]

(C) 2020 by the authors. Licensee MDPI, Basel, Switzerland. This article is an open access article distributed under the terms and conditions of the Creative Commons Attribution (CC BY) license (http://creativecommons.org/licenses/by/4.0/). 